Check for updates

Cite this: Chem. Sci., 2019, 10, 7091

๑ All publication charges for this article have been paid for by the Royal Society of Chemistry

Received 25th March 2019

Accepted 12th June 2019

DOI: $10.1039 / c 9 s c 01463 b$

rsc.li/chemical-science

\section{Phosphorus corrole complexes: from property tuning to applications in photocatalysis and triplet-triplet annihilation upconversion $\dagger$}

\author{
Atif Mahammed, $\dot{\dagger}^{\mathrm{a}}$ Kepeng Chen, (D) $\dot{\dagger}^{\mathrm{b}}$ Jenya Vestfrid, ${ }^{\mathrm{c}}$ Jianzhang Zhao (D) *b \\ and Zeev Gross iD *a
}

\begin{abstract}
Efficient triplet photosensitizers are important for fundamental photochemical studies and applications such as triplet-triplet annihilation upconversion (TTA UC), photoredox catalytic organic reactions and photovoltaics. We now report a series of phosphorus corrole compounds as efficient visible lightharvesting metal-free triplet photosensitizers. While the heavy-atom-free phosphorus corroles show absorption in the visible spectral region (centered at $573 \mathrm{~nm}$ ) and have a decent triplet state quantum yield $\left(\Phi_{\Delta}=49 \%\right)$, iodo-substitution on the corrole core induces red-shifted absorption (589 $\mathrm{nm}$ ) and improves intersystem crossing significantly $\left(\Phi_{\Delta}=67 \%\right)$. Nanosecond transient absorption spectra confirm triplet state formation upon photoexcitation $\left(\tau_{\top}=312 \mu \mathrm{s}\right)$ and the iodinated derivatives also display near IR phosphorescence in fluid solution at room temperature $\left(\lambda_{\mathrm{em}}=796 \mathrm{~nm}, \tau_{\mathrm{p}}=412 \mu \mathrm{s}\right)$. Both singlet oxygen $\left({ }^{1} \mathrm{O}_{2}\right)$ and superoxide radical anions $\left(\mathrm{O}_{2}^{-\cdot}\right)$ may be produced with the phosphorus corroles, which are competent photocatalysts for the oxidative coupling of benzylamine (the Aza Henry reaction). Very efficient TTA UC was observed with the phosphorus corroles as triplet photosensitizers and perylene as the triplet acceptor, with upconversion quantum yields of up to $\Phi_{\cup \mathrm{C}}=38.9 \%$ (a factor of 2 was used in the equation) and a very large anti-Stokes effect of $0.5 \mathrm{eV}$.
\end{abstract}

\section{Introduction}

Energy up-conversion is a highly desirable process, as incident photons of a given energy are converted into photons with higher energy. ${ }^{1}$ It is important for applications in many fields including photovoltaic devices, ${ }^{2,3}$ luminescent probes for bioimaging, ${ }^{4-9}$ photocatalysis by low-energy photons, ${ }^{10-15}$ and photoinduced charge separation. ${ }^{16-19}$ When the efficiency of upconversion is high enough, low-power up-conversion may be used to harness low-energy photons that, otherwise, would be lost in practical applications. For instance, it could be applied to solar cells to harvest the red and NIR part of the solar spectrum, which has energy lower than the band-gap of the employed photoactive material. ${ }^{20}$ Its applicability for bioimaging is even

${ }^{a}$ Schulich Faculty of Chemistry, Technion-Israel Institute of Technology, Haifa 32000, Israel. E-mail: chr10zg@tx.technion.ac.il

${ }^{b}$ State Key Laboratory of Fine Chemicals, School of Chemical Engineering, Dalian University of Technology, E-208 West Campus, 2 Ling-Gong Road, Dalian 116024, P. R. China. E-mail: zhaojzh@dlut.edu.cn

'Department of Chemistry, University of Toronto, Canada

$\dagger$ Electronic supplementary information (ESI) available: Experimental procedures, computational details, molecular structure characterization, crystal structures, crystallographic data, electrochemical data and additional spectra. CCDC 1888512-1888513. For ESI and crystallographic data in CIF or other electronic format see DOI: 10.1039/c9sc01463b

$\ddagger$ These authors contributed equally to this work. more intriguing, since excitation in the NIR region offers advantages of deeper depth penetration, suppressed background fluorescence and reduced phototoxicity. ${ }^{21}$

One possible strategy for photon upconversion comes from harnessing sensitized triplet-triplet annihilation (TTA) photochemistry. Higher energy photons are generated from the absorption of lower energy light by an efficient triplet sensitizer through sequential, highly allowed one-photon absorption, subsequent intersystem crossing (ISC) and intermolecular triplet-triplet energy transfer (TTET) to the energy acceptor, and the population of the $S_{1}$ state of the triplet acceptor by the TTA process. ${ }^{1,2,22,23}$ In essence, the energy stored in two sensitized triplet molecules is combined to produce one higher energy singlet state and a corresponding ground-state species. TTA upconversion is particularly interesting for its advantages over conventional upconversion methods where two photons require excitation with coherent light sources (lasers) of very highpower density (e.g. nonlinear optical crystals). In contrast, TTA upconversion requires only noncoherent low-power excitation and is characterized by intense absorption of excitation light as well as high upconversion quantum yields., ${ }^{\mathbf{1 , 2 , 1 1}}$ This phenomenon was first introduced by Parker and Hatchard in the 1960s, utilizing organic chromophores as triplet sensitizers, which however exhibited low intersystem crossing efficiencies thereby limiting upconversion. ${ }^{24,25}$ TTA upconversion has witnessed great development in recent years. ${ }^{26,27}$ 
One challenge for the development of TTA upconversion is the limited availability of appropriate triplet photosensitizers. ${ }^{\mathbf{1 1}}$ Commonly investigated typical triplet photosensitizers used for TTA upconversion include porphyrin and phthalocyanine complexes, ${ }^{28}$ phosphorescent transition metal complexes with diimine ligands, ${ }^{29}$ bromo- and iodo-organic chromophores, ${ }^{30}$ and a few heavy-metal-free triplet photosensitizers. ${ }^{31}$ It is relatively easy to study the intermolecular triplet energy transfer of phosphorescent photosensitizers, however, when the triplet sensitizer is non-phosphorescent, quenching must be measured by the variation of the lifetime of the $T_{1}$ excited state of the sensitizer with the aid of time-resolved transient absorption spectroscopy. ${ }^{\mathbf{1 1}}$ During the last decade, we and other groups have studied corroles chelated by metal ions such as gold and iridium as triplet photosensitizers, by taking advantage of the heavy atom effect for inducing efficient singlet-triplet interconversion (ISC). ${ }^{32-37}$ In parallel, we have also introduced corroles chelating non-redox active and much more abundant elements, such as $\mathrm{Ga}, \mathrm{Al}$, and $\mathrm{P}$, wherein the non-radiative decay of the $S_{1}$ state can be inhibited. ISC enhancement was encouraged by bromides or iodides, ${ }^{38,39}$ which in the corrole case are present on the corrole skeleton and hence not released to the environment. ${ }^{\mathbf{4 0 , 4 1}}$ Corroles with reasonable ISC probability have been introduced for photodynamic therapy, ${ }^{\mathbf{3 4 , 4 2 , 4 3}}$ molecular spintronics, ${ }^{44}$ energy transfer studies, ${ }^{45}$ and oxygen sensing. ${ }^{35}$ But to the best of our knowledge, corroles were rarely used for TTA upconversion, ${ }^{32,46}$ despite the easy tuning of their redox and photophysical properties and the extremely high stability regarding demetallation.

\section{Results and discussion}

\section{Rational design of the compounds}

We decided to focus our investigations on compounds composed of non-toxic and non-precious $\mathrm{C}, \mathrm{H}, \mathrm{F}, \mathrm{I}$, and $\mathrm{P}$ elements only (Scheme 1), as opposed to the intensively used $\mathrm{Ru} / \mathrm{Pt} / \mathrm{Ir}$ photosensitizers. The most prominent feature of corroles, particularly meso- $\mathrm{C}_{6} \mathrm{~F}_{6}$-substituted derivatives, is strong fluorescence. As this testifies for very little non-radiative loss of energy, ${ }^{47}$ the hypothesis was that halogenation of the corrole core will increase the ISC probability and consequently the yields of the triplet excited states. Another advantage is that iodination increases red shifts of the absorbance/emission maxima and also redox potentials. The latter aspect is also tunable by the axial ligands and the number of $\mathrm{F}$ atoms in the meso-aryl substituents. The novelty regarding the synthetic part was to move away from hydroxo- and oxo-phosphorus corroles, which are substitution labile (converted into each other and react with solvents), ${ }^{\mathbf{4 7} 48}$ to a well-defined series of substitutioninert trans-difluorophosphorus corroles, so as to allow for the systematic research described in this paper. ${ }^{49}$

Treatment of phosphorus corroles with $\mathrm{N}$-iodosuccinimide (NIS) or with 1,3-diiodo-5,5-dimethylhydantoin (DIH) led to selective iodination on the corrole macrocycle (Scheme 1$).{ }^{41}$ The axial hydroxyl ligands of these iodinated complexes were exchanged with fluorides after treatment with aqueous hydrofluoric acid (Scheme 1). ${ }^{41}$ This transformation resulted in very significant and enlightening changes in the NMR spectra (Fig. S1-S17 $\dagger$ ). The ${ }^{1} \mathrm{H}$ resonances of hydroxyl groups disappear and the ${ }^{19} \mathrm{~F}$ signals of fluoride ligands appear, well separated from those of $\mathrm{C}_{6} \mathrm{~F}_{5}$ and $\mathrm{C}_{6} \mathrm{H}_{3} \mathrm{~F}_{2}$ aryl groups. Another prominent feature is the $J \cong 830 \mathrm{~Hz}$ mutual splitting coupling constant between the axial fluorides (appear as a doublet) and phosphorus (appears as a triplet).

\section{X-ray crystallography}

Being concerned about the effect of the rather large iodosubstituents on the planarity of the complexes, the X-ray structures of $\mathbf{1 P F _ { 2 }}-\mathbf{I}_{\mathbf{4}}$ and $\mathbf{2} \mathbf{P F}_{\mathbf{2}}-\mathbf{I}_{\mathbf{4}}$ were obtained. Fig. 1 clearly demonstrates that the deviations of the $\beta$-pyrrole substituted moieties of $\mathbf{1} \mathbf{P F}_{\mathbf{2}}-\mathbf{I}_{\mathbf{4}}$ and $\mathbf{2} \mathbf{P F}_{\mathbf{2}}-\mathbf{I}_{\mathbf{4}}$ relative to the average mean plane of all 23 carbon atoms are quite small, in the range of 0.032-0.287 $\AA$ for $2 \mathbf{P F}_{2}-\mathbf{I}_{4}$ and $0.000 \AA$ for the extremely planar $\mathbf{1} \mathbf{P F}_{2}-\mathbf{I}_{\mathbf{4}}$. The peripheral phenyl rings are not in coplanar geometry with the corrole core, and thus the $\pi$-conjugation framework of the substituted corroles is not heavily affected by the phenyl rings.

\section{UV-vis absorption and photoluminescence of the compounds}

The UV-vis absorption spectrum of $\mathbf{1} \mathbf{P F}_{2}$ displays an intense absorption band at $404 \mathrm{~nm}$ and weaker ones in the range of 500-600 nm (Fig. 2a). The former is attributed to the higher-

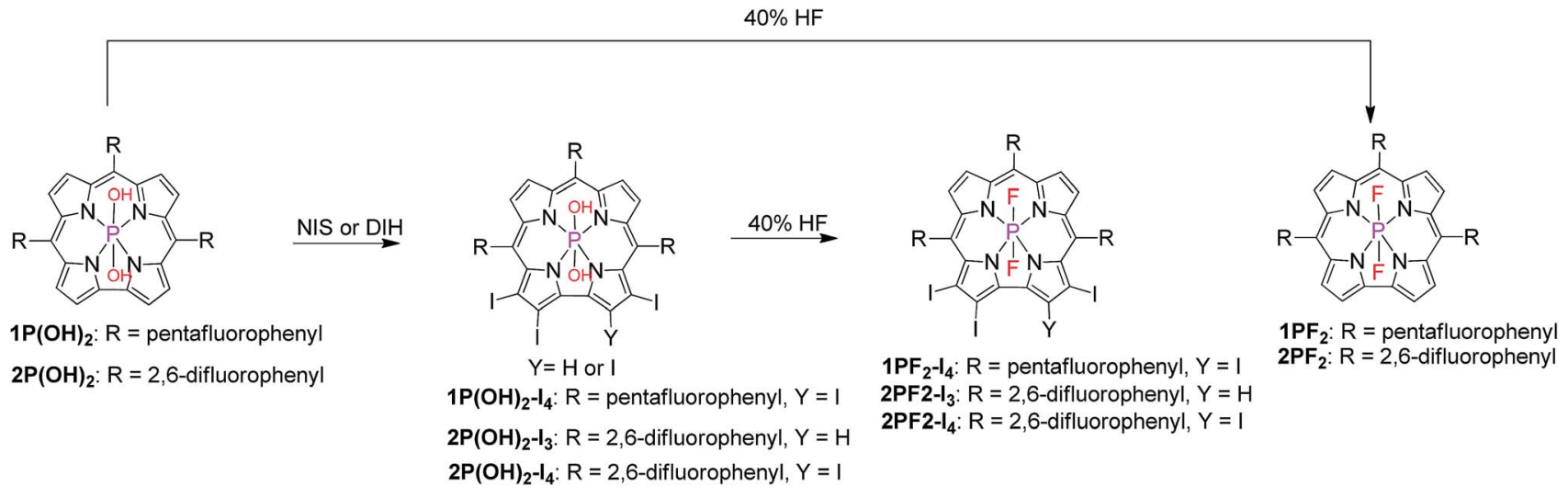

Scheme 1 Axial ligand exchange and macrocycle iodination of phosphorus corroles. 

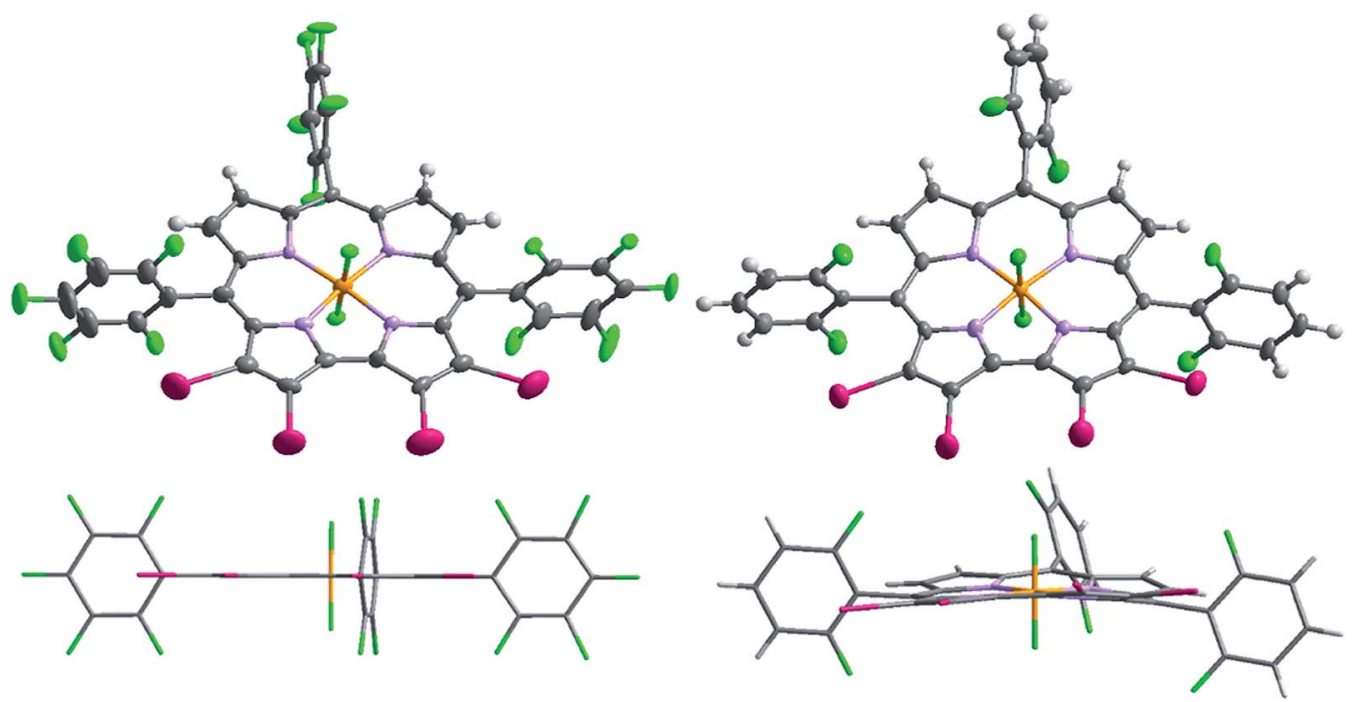

Fig. 1 Top and side views of the single-crystal molecular structure of $1 \mathrm{PF}_{2}-\mathrm{I}_{4}$ (left) and $2 \mathrm{PF}_{2}-\mathrm{I}_{4}$ (right).

energy and more allowed Soret band and the latter to lower energy and symmetry-forbidden $\mathrm{Q}$ bands of the corrole core. Similar absorptions were observed for $\mathbf{1 P F}_{2}-\mathbf{I}_{\mathbf{4}}$, but red-shifted by $19 \mathrm{~nm}$ for the Soret band and $16 \mathrm{~nm}$ for the Q bands, and the absorption of the lower energy band at $589 \mathrm{~nm}$ is intensified as compared to that of $\mathbf{1 P F}_{\mathbf{2}}$. Intensified absorption in the redshifted region is beneficial for the application of these heavymetal-free photosensitizers. Similar absorption profiles were observed for $2 \mathbf{P F}_{2}, \mathbf{2} \mathbf{P F}_{2}-\mathbf{I}_{3}$ and $2 \mathbf{P F}_{2}-\mathbf{I}_{\mathbf{4}}$ (Fig. $2 b$ ).

In terms of luminescence properties, there is a significant difference between $\mathbf{1} \mathbf{P F}_{2}$ and $\mathbf{1} \mathbf{P F}_{2}-\mathbf{I}_{\mathbf{4}}$ (Fig. 3). $\mathbf{1} \mathbf{P F}_{\mathbf{2}}$ displays emission bands in the range of 525-700 nm in different organic solvents (DCM, $\mathrm{CH}_{3} \mathrm{CN}$, and $\mathrm{MeOH}$ ), with significant vibrational progression (Fig. 3a). This is a typical emission feature of corroles, which is also similar to the emission of porphyrin compounds. $\mathbf{1 P F}_{2}-\mathbf{I}_{\mathbf{4}}$ has a similar emission profile in the same solvents (Fig. $3 \mathrm{~b}$ ), but the intensity is much weaker (Fig. 3c). Instead, a new emission band at $796 \mathrm{~nm}$ was observed in deaerated solutions of $\mathbf{1} \mathbf{P F}_{2}-\mathbf{I}_{\mathbf{4}}$ at room temperature, which was completely quenched in aerated solution (Fig. 3d), consistent with phosphorescence. ${ }^{41}$ No phosphorescence was observed for the non-iodinated corroles under
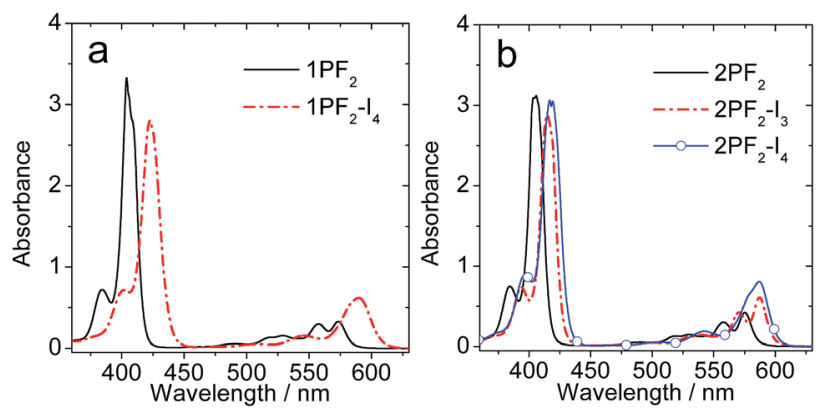

Fig. 2 UV-vis absorption spectra of (a) $1 \mathrm{PF}_{2}$ and $1 \mathrm{PF}_{2}-\mathrm{I}_{4}$; (b) $2 \mathrm{PF}_{2}$, $2 \mathrm{PF}_{2}-\mathrm{I}_{3}$ and $2 \mathrm{PF}_{2}-\mathrm{I}_{4} . \mathrm{C}=1.0 \times 10^{-5} \mathrm{M}$ in toluene, $20^{\circ} \mathrm{C}$. the same conditions (Fig. S28†), consistent with previous demonstration that phosphorescence of free base corroles is only recognizable at low temperature $(77 \mathrm{~K}) .^{50}$ This observation can be attributed to the enhanced ISC in the iodinated corroles, i.e. the heavy atom effect. ${ }^{51-53}$ The photophysical parameters for the phosphorus corroles in toluene are compiled in Table $1 . \mathbf{1 P F}_{2}$ and $\mathbf{2} \mathbf{P F}_{2}$ are fluorescent with quantum yields of $10 \%$ and $13 \%$ and fluorescence lifetimes of $3.3 \mathrm{~ns}$ and $3.7 \mathrm{~ns}$, respectively. Iodination of these complexes at the corrole macrocycle reduces the fluorescence quantum
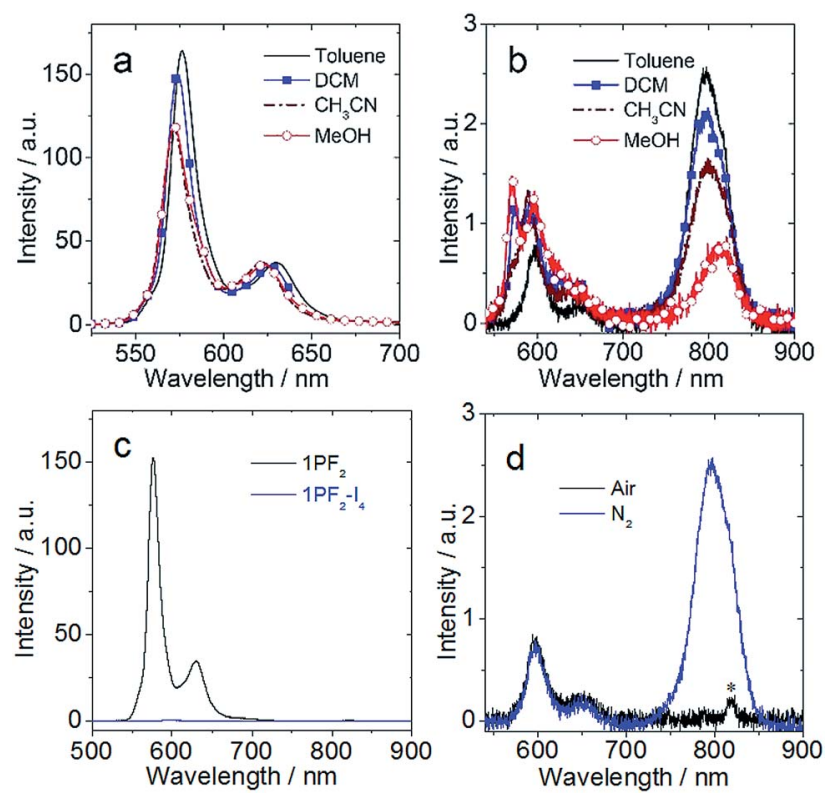

Fig. 3 Emission spectra ( $\lambda_{\mathrm{ex}}=410 \mathrm{~nm}$, optically matched solutions were used $(A=0.454), 20^{\circ} \mathrm{C}$ ) of (a) $1 \mathrm{PF}_{2}$ in four $\mathrm{N}_{2}$ saturated solvents; (b) $1 \mathrm{PF}_{2}-\mathrm{I}_{4}$ in four $\mathrm{N}_{2}$ saturated solvents; (c) $1 \mathrm{PF}_{2}$ and $1 \mathrm{PF}_{2}-\mathrm{I}_{4}$ in $\mathrm{N}_{2}$ saturated toluene; (d) $1 \mathrm{PF}_{2}-\mathrm{I}_{4}$ in air- and $\mathrm{N}_{2}$ - saturated toluene (" $*$ " denotes the secondary transmission of the monochromator, due to the excitation wavelength). 
Table 1 Photophysical properties of the compounds

\begin{tabular}{|c|c|c|c|c|c|c|c|}
\hline & $\lambda_{\mathrm{abs}}{ }^{a} / \mathrm{nm}$ & $\varepsilon^{b}$ & $\lambda_{\mathrm{em}}{ }^{c} / \mathrm{nm}$ & $\tau_{\mathrm{L}}{ }^{d}$ & $\Phi_{\mathrm{L}}^{e}(\%)$ & $\tau_{\mathrm{T}}^{f}(\mu \mathrm{s})$ & $\Phi_{\Delta}^{g}(\%)$ \\
\hline $1 \mathrm{PF}_{2}$ & $404,556,573$ & $3.31,0.30,0.33$ & $577^{h}, 630^{h}$ & $3.3^{i}$ & $10^{j}$ & 312 & 49 \\
\hline $1 \mathrm{PF}_{2}-\mathrm{I}_{4}$ & $423,544,589$ & $2.80,0.15,0.62$ & $598^{h}, 647^{h}, 796^{k}$ & $1.2^{i}, 412^{l}$ & $0.05^{j}, 0.27^{m}$ & 179 & 67 \\
\hline $2 \mathrm{PF}_{2}-\mathrm{I}_{3}$ & $415,570,587$ & $2.88,0.42,0.61$ & $591^{h}, 645^{h}, 786^{k}$ & $0.48^{i}, 338^{l}$ & $0.12^{j}, 0.15^{m}$ & 127 & 60 \\
\hline $2 \mathrm{PF}_{2}-\mathrm{I}_{4}$ & $417,570,587$ & $3.06,0.42,0.61$ & $592^{h}, 638^{h}, 795^{k}$ & $0.14^{i}, 530^{l}$ & $0.11^{j}, 0.36^{m}$ & 181 & 71 \\
\hline
\end{tabular}

${ }^{a}$ In toluene, $c=1.0 \times 10^{-5}$ M. ${ }^{b}$ Molar absorption coefficient $\times 10^{5}, \mathrm{M}^{-1} \mathrm{~cm}^{-1} \cdot{ }^{c}$ Emission wavelength, in toluene. ${ }^{d}$ Luminescence lifetimes. ${ }^{e}$ Luminescence (fluorescence and phosphorescence) quantum yields, with $\mathrm{Ru}(\mathrm{bpy})_{3}\left[\mathrm{PF}_{6}\right]_{2}$ (in deaerated $\left.\mathrm{CH}_{3} \mathrm{CN}, \Phi_{\mathrm{P}}=9.5 \%\right)$ as in ref. 54 .

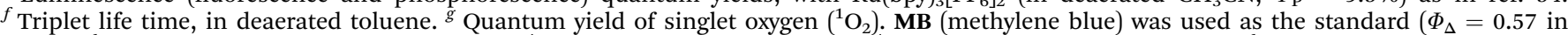
DCM). ${ }^{h}$ Fluorescence emission wavelength. ${ }^{i}$ Fluorescence lifetimes (ns). ${ }^{j}$ Fluorescence quantum yields. ${ }^{k}$ Phosphorescence emission wavelength. ${ }^{l}$ Phosphorescence lifetimes $(\mu \mathrm{s}) .{ }^{m}$ Phosphorescence quantum yields.

yields and the fluorescence lifetimes dramatically, and the complexes become phosphorescent at longer wavelengths (about $800 \mathrm{~nm}$ ) with lifetimes of several hundred microseconds (Table 1). An in-depth investigation of the fluorescence lifetimes revealed a mono-exponential decay with a lifetime of $3.3 \mathrm{~ns}$ for $\mathbf{1 P F}_{2}$ (Fig. 4a), corresponding to the decay of the bright $\mathrm{S}_{1}$ state of the corrole. Interestingly, for $\mathbf{1 P F}_{2}-\mathbf{I}_{\mathbf{4}}$, a bi-exponential decay was observed for the emission at $598 \mathrm{~nm}$ (fluorescence, Fig. 4b). A fast component (64\%) is with a lifetime of $0.065 \mathrm{~ns}$, which is close to the instrument response function (IRF). A long-lived (36\%) component was observed with a lifetime of $3.0 \mathrm{~ns}$. We attribute the fast-decaying component to the ISC, and the relatively longlived component is due to the presence of the activation barrier for ISC, i.e., a minor component of the excited molecules does not undergo ISC. ${ }^{55}$ This is consistent with the low-intensity fluorescence emission seen in Fig. 3c. In other words, there is a nonunity transition probability for ISC. Similar phenomena are also very often observed for molecular systems used for photo-induced electron transfer. ${ }^{56}$ The decay at $795 \mathrm{~nm}$ was also monitored and its lifetime was determined as $412 \mu \mathrm{s}$ (Fig. 4c). Considering the large Stokes shift, the long lifetime, and the sensitivity of this emission band to $\mathrm{O}_{2}$, the emission at $795 \mathrm{~nm}$ is assigned to the phosphorescence of the iodinated corrole. Room temperature phosphorescence is rarely obtained for organic chromophores with a large $\pi$-conjugation framework, but is displayed for iodinated chromophores such as iodinated Bodipy derivatives. ${ }^{19}$ Multiple iodo-substitutions on the corrole framework are clearly beneficial for obtaining phosphorescence. ${ }^{57}$ The luminescence lifetimes of the compounds in different solvents are summarized in Table S1, $\dagger$ which reveals that $\mathbf{2} \mathbf{P F}_{2}$ without iodo substituents has a fluorescence lifetime that is similar to that of $\mathbf{1 P F}_{2}$. Similar results were observed for $\mathbf{2} \mathbf{P F}_{2}-\mathbf{I}_{3}$ and $\mathbf{2} \mathbf{P F}_{2}-\mathbf{I}_{\mathbf{4}}$, compared with $\mathbf{1 P F}_{2}-\mathbf{I}_{\mathbf{4}}$ : all of them have fluorescence lifetimes that are $10-20$ times smaller relative to their non-substituted analogs, and phosphorescence lifetimes in the range of several hundred microseconds.

As a preliminary evaluation of the ISC efficiency of the corroles, the singlet oxygen quantum yields $\left(\Phi_{\Delta}\right)$ were measured. For the non-iodinated corroles $\mathbf{1} \mathbf{P F}_{2}$ and $\mathbf{2} \mathbf{P F}_{2}$, the $\Phi_{\Delta}$ values are $49 \%$ and $46 \%$, respectively. These results indicate that while ISC is quite efficient even for $\mathbf{1} \mathbf{P F}_{2}$ and $\mathbf{2} \mathbf{P F}_{2}$, upon iodination, the $\Phi_{\Delta}$ increases to $60-71 \%$ (Table 1), which is clearly attributed to the heavy atom effect of the iodo-substituents.

\section{Nanosecond transient absorption spectroscopy: triplet excited states}

In order to confirm the triplet state production of the corroles upon photoexcitation, the nanosecond transient absorption spectra of the compounds were studied (Fig. 5). For $\mathbf{1 P F}_{2}$,
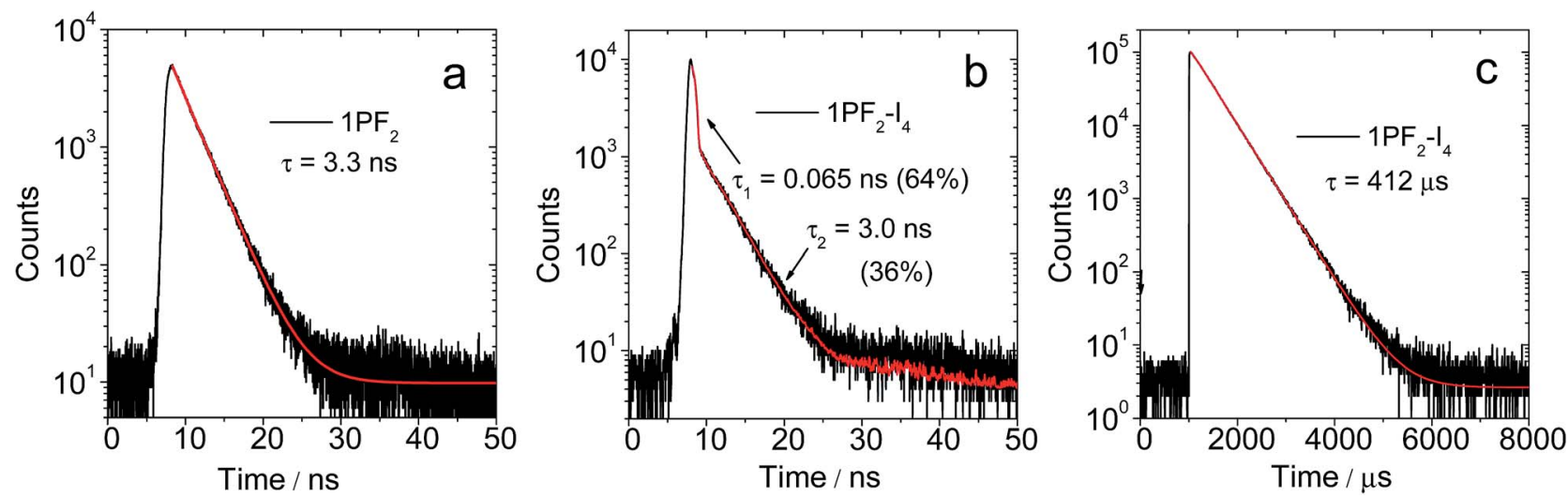

Fig. 4 Decay traces of the luminescence of (a) $1 \mathrm{PF}_{2}$ at $577 \mathrm{~nm}$ (fluorescence band) in toluene; (b) $1 \mathrm{PF}_{2}-\mathrm{I}_{4}$ at $598 \mathrm{~nm}$ (fluorescence band) in deaerated toluene; (c) $1 \mathrm{PF}_{2}-\mathrm{I}_{4}$ at $795 \mathrm{~nm}$ (phosphorescence band) in deaerated toluene. (b) Excited with a picosecond pulsed laser for the fluorescence band $\left(\lambda_{\mathrm{ex}}=405 \mathrm{~nm}\right)$, and excited with a microsecond flash lamp for the phosphorescence peak at $\lambda_{\mathrm{ex}}=420 \mathrm{~nm}, \mathrm{C}=1.0 \times 10^{-5} \mathrm{M}$, $20{ }^{\circ} \mathrm{C}$. 

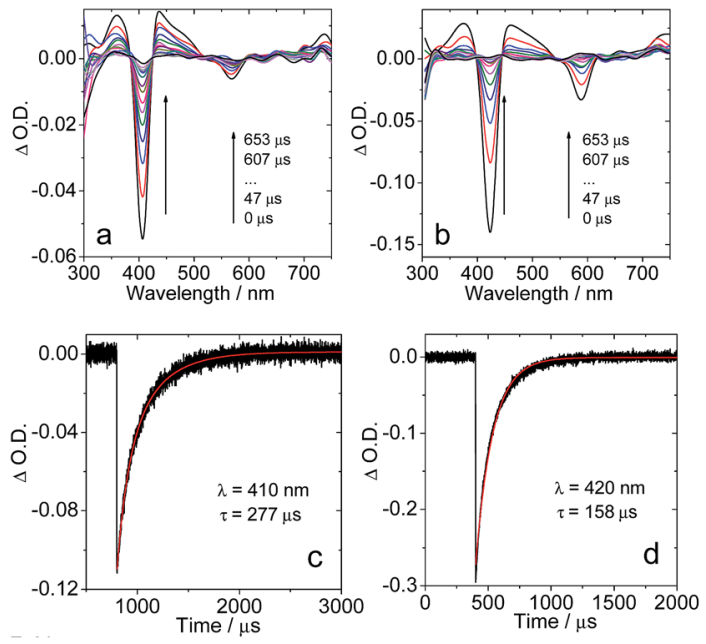

Fig. 5 Nanosecond transient absorption spectra of (a) $1 \mathrm{PF}_{2}\left(\lambda_{\text {ex }}=556\right.$ $\mathrm{nm})$ and (b) $1 \mathrm{PF}_{2}-\mathrm{I}_{4}\left(\lambda_{\text {ex }}=589 \mathrm{~nm}\right)$; decay trace of the transients of (c) $1 \mathrm{PF}_{2}$ at $410 \mathrm{~nm}$ and (d) $1 \mathrm{PF}_{2}-\mathrm{I}_{4}$ at $420 \mathrm{~nm}$. Excited with a nanosecond pulsed laser. $\mathrm{C}=2.5 \times 10^{-6} \mathrm{M}$ in deaerated toluene, $20^{\circ} \mathrm{C}$.

a significant ground state bleaching band at $405 \mathrm{~nm}$ was observed upon photo-excitation. However, the ground state band (GSB) at $567 \mathrm{~nm}$ is much weaker, apparently due to the much smaller molar extinction coefficients of the ground state absorption of the compound in this region (Fig. 2), as well as the possible superimposition of the GSB with the excited state absorption (ESA) band in this region. This effect is much more significant in the range of 350-500 nm, where the ESA band also overlaps with the GSB. The transient was determined to have a lifetime of $277 \mu \mathrm{s}$ in deaerated solution (Fig. 5c). This was reduced by 3 orders of magnitude (266 ns) in aerated solution (Fig. S35 $\dagger$ ), thus confirming that the transient absorption is of the triplet-excited state of the corrole. It should be pointed out that for a long-lived triplet state that is formed with high quantum yield (Table 1), self-quenching of the triplet state might be significant, i.e. that the observed triplet state lifetime might be concentration dependent. The intrinsic triplet state was determined by extrapolation to indefinite diluted concentration, uncovering it to be $312 \mu$ s (Table 1 and Fig. S58, S59†).
Similar transient absorption spectra were observed for $\mathbf{1} \mathbf{P F}_{\mathbf{2}} \mathbf{-}$ $\mathbf{I}_{\mathbf{4}}$ (Fig. 5b), and by extrapolation to indefinite diluted concentration, its triplet state lifetime was determined as $179 \mu$ s (Table 1). The shorter triplet state lifetime of $\mathbf{P P F}_{2}-\mathbf{I}_{\mathbf{4}}$ as compared to $\mathbf{1 P F}_{2}$ may be attributed to the heavy atom effect in $\mathbf{P P F}_{2}-\mathbf{I}_{\mathbf{4}}$. The triplet states of other compounds were also studied with nanosecond transient absorption spectra: long-lived triplet states were observed in all cases (Fig. S33 $\dagger$ ). The ESA bands of the compounds in the region of 300-550 $\mathrm{nm}$ can be assigned to the transition of $\mathrm{T}_{1}$ to higher triplet states, i.e. $\mathrm{T}_{1} \rightarrow \mathrm{T}_{n}$ based on TD-DFT computations (Table $\mathrm{S} 2 \dagger$ ). Interestingly, some previously reported corroles show much shorter triplet state lifetimes. For instance, corroles with non-fluorinated phenyl rings show triplet state lifetimes in the range of $0.82-3.50 \mu \mathrm{s.}^{58}$ Comparison with other heavy atom containing corroles $(\mathrm{Br}, \mathrm{Au}$, Ir, Os, and Re) discloses typical excited state life times in the range of 19-183 $\mu \mathrm{s}$, which identifies the iodinated $\mathrm{P}$ corroles as among the complexes with the largest excited-state lifetimes. $^{32,35,46,59,60}$ It should be pointed out that the strong absorption of visible light and the long-lived triplet states of these corroles are beneficial for these compounds to be used as triplet photosensitizers, because these are the desired photophysical properties for intermolecular energy- or electrontransfer (vide infra).

The spatial confinement of the triplet state wavefunction of the corroles was investigated by DFT optimization studies (Fig. 6). For both $\mathbf{1} \mathbf{P F}_{\mathbf{2}}$ and $\mathbf{1} \mathbf{P F}_{\mathbf{2}}-\mathbf{I}_{\mathbf{4}}$, the triplet state wavefunction is largely confined on the corrole $\pi$-conjugation framework, although it also spreads slightly to the peripheral perfluorinated phenyl moieties (Fig. 6).

Although different torsion angles between the peripheral $\mathrm{C}_{6} \mathrm{~F}_{5}$ ring and the corrole core of the two compounds were observed, i.e. the dihedral angles are $65^{\circ}$ and $78^{\circ}$ for $\mathbf{1 P F}_{2}$ and $\mathbf{1} \mathbf{P F}_{\mathbf{2}}-\mathbf{I}_{\mathbf{4}}$, respectively, the confinement of the triplet states is almost the same. These different dihedral angles may safely be attributed to the iodine substitution in $\mathbf{1 P F}_{2}-\mathbf{I}_{\mathbf{4}}$, which exerts some steric hindrance on the rotation of the aryl rings. The confinement of the triplet state wavefunction of the triplet state of corroles was previously studied by time-resolved electron paramagnetic resonance (TREPR), but the confinement of the triplet state was not discussed in detail. ${ }^{61}$

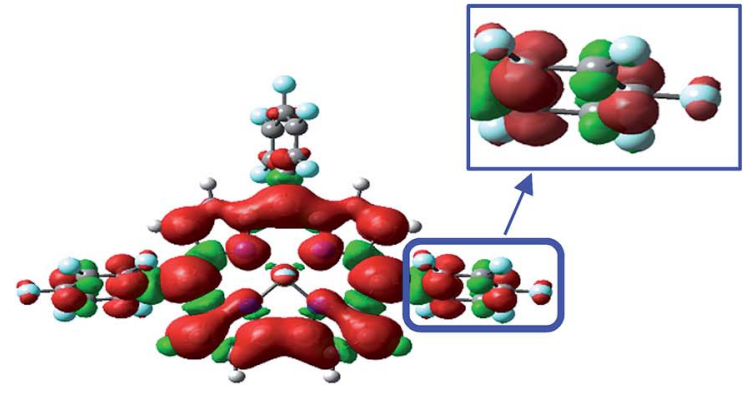

(a)

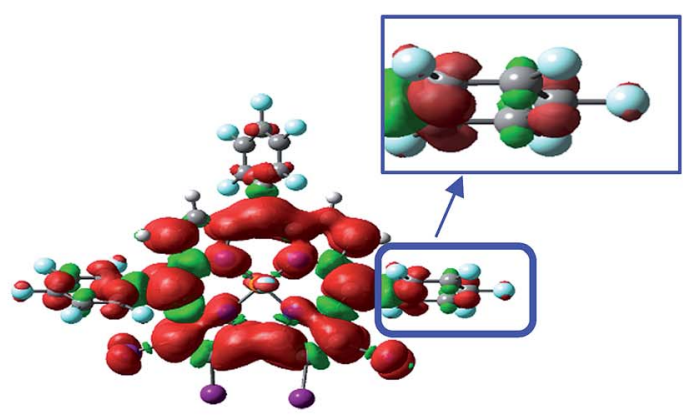

(b)

Fig. 6 Spin density surfaces of (a) $1 \mathrm{PF}_{2}$ (calculated at the B3LYP/6-31G(d) level with Gaussian 09W) and (b) $1 \mathrm{PF} \mathrm{F}_{2}-\mathrm{I}_{4}$ (calculated at the B3LYP/ GENECP level with Gaussian 09W) at the optimized triplet state geometry. 


\section{Production of the corrole radical anions by reversible photoreduction}

The motivation for investigating photo-driven intermolecular electron transfer between the corroles and a sacrificial electron donor (triethylamine, $\mathrm{Et}_{3} \mathrm{~N}$ ) was to gain fundamental information that is relevant for potential applications of the corroles as photocatalysts. UV-vis examination upon continuous white light irradiation of an anaerobic solution of $\mathbf{1 P F}_{2} / \mathrm{Et}_{3} \mathrm{~N}$ disclosed that the absorption bands at $400 \mathrm{~nm}$ and $567 \mathrm{~nm}$ decreased, whereas new absorption bands in the region of 350-450 $\mathrm{nm}$ and 575$650 \mathrm{~nm}$ appeared (Fig. 7a, the ground state difference absorption spectra). These new absorption bands may safely be attributed to the radical anion of the corroles. ${ }^{62}$ Interestingly, the photo-reduction process is reversible, clearly evident by the recovery of the pink color of the corrole solution after exposure of the irradiated solution to air (Fig. 7b) i.e., $\mathbf{1 P F}_{2}{ }^{-\boldsymbol{e}}$ is oxidized to the neutral form of the corroles by dioxygen in air. The process of light-induced reduction of $\mathbf{1} \mathbf{P F}_{2}$ to $\mathbf{1 P F}_{2}{ }^{-\cdot}$ and reoxidation of the latter by oxygen may in fact be repeated for several cycles without degradation of the corrole, as illustrated in Fig. 7c.

We also studied the interaction of molecular oxygen with the triplet excited state and the photo-generated radical anion of the corroles (Fig. 8): singlet oxygen $\left({ }^{1} \mathrm{O}_{2}\right)$ and superoxide radical anions $\left(\mathrm{O}_{2}{ }^{-\cdot}\right)$ are expected to be formed by the two species, respectively. Spin traps selective for ${ }^{1} \mathrm{O}_{2}$ (2,2,6,6-tetramethyl-4piperidone, TEMP) and $\mathrm{O}_{2}{ }^{-\cdot}(5,5$-dimethyl-1-pyrroline- $N$-oxide, DMPO) were used in combination with $\mathbf{1 P F}_{2}$ and photoirradiation, in the presence/absence of $\mathrm{Et}_{3} \mathrm{~N}$. The results depicted in Fig. 8 reveal the formation of the ${ }^{1} \mathrm{O}_{2}$-scavenged product of TEMP only when $\mathrm{Et}_{3} \mathrm{~N}$ was absent (Fig. 8a and b) and of the $\mathrm{O}_{2}{ }^{-}$-DMPO product only when $\mathrm{Et}_{3} \mathrm{~N}$ was present (Fig. 8c and d). These studies clarify that both ${ }^{1} \mathrm{O}_{2}$ and $\mathrm{O}_{2}{ }^{-\cdot}$ can be produced under appropriate conditions with the phosphorus corroles. ${ }^{63}$ Similar results were obtained for $2 \mathbf{P F}_{2}-\mathbf{I}_{\mathbf{3}}$ and $\mathbf{2} \mathbf{P F}_{2}-\mathbf{I}_{\mathbf{4}}$ (Fig. S49 and S50 $\dagger$ ). The ability of these phosphorus corroles to photooxidize $\mathrm{Et}_{3} \mathrm{~N}$ is attributed to their high triplet reduction potential (Table 2) relative to the onset oxidation potential of
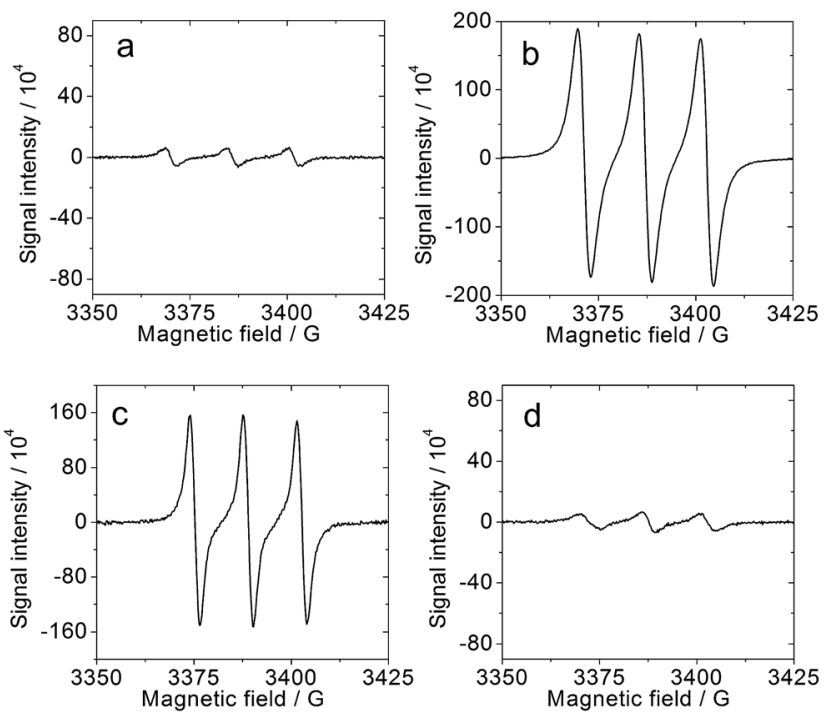

Fig. 8 ESR spectrum of the mixtures of $1 \mathrm{PF}_{2}$ and TEMP (spin trapping reagent for ${ }^{1} \mathrm{O}_{2}$ ) or DMPO (spin trapping reagent for $\mathrm{O}_{2}{ }^{-\cdot}$ ) upon photo-irradiation. (a) $1 \mathrm{PF}_{2}\left(1.0 \times 10^{-5} \mathrm{M}\right), \mathrm{Et}_{3} \mathrm{~N}(0.25 \mathrm{M})$ and TEMP $(0.1$ $\mathrm{M})$; (b) $1 \mathrm{PF}_{2}\left(1.0 \times 10^{-5} \mathrm{M}\right)$ and $\operatorname{TEMP}(0.1 \mathrm{M})$; (c) $1 \mathrm{PF}_{2}\left(1.0 \times 10^{-5} \mathrm{M}\right)$, $\mathrm{DMPO}(0.01 \mathrm{M}), \mathrm{Et}_{3} \mathrm{~N}(0.25 \mathrm{M})$; (d) $1 \mathrm{PF}_{2}\left(1.0 \times 10^{-5} \mathrm{M}\right), \mathrm{DMPO}(0.01 \mathrm{M})$. In air-saturated $\mathrm{CH}_{3} \mathrm{CN}$. The samples were photo-irradiated with a $\mathrm{Xe}$ lamp for $60 \mathrm{~s}\left(23 \mathrm{~mW} \mathrm{~cm}^{-2}\right), 20^{\circ} \mathrm{C}$.

$\mathrm{Et}_{3} \mathrm{~N}(0.65 \mathrm{~V}$, Fig. 9). The triplet excited state reduction potential of $2 \mathbf{P F}_{2}(0.52 \mathrm{~V}$, Table 2$)$ is however lower than the onset oxidation potential of $\mathrm{Et}_{3} \mathrm{~N}$. This explains the inability of $\mathbf{2} \mathbf{P F}_{2}$ to be photo-reduced by TEA in the absence of $\mathrm{O}_{2}$ (Fig. S38 $\dagger$ ).

\section{Phosphorus corroles as photocatalysts for redox-involving organic reactions}

Encouraged by the photo- and electro-chemical properties uncovered for the phosphorus corroles, it is suggested that they might be good photocatalysts for redox-involving organic reactions. The Aza Henry reaction was selected as it is an oxidative coupling of benzylamine with itself. The literature points towards two possible mechanisms for the role of the
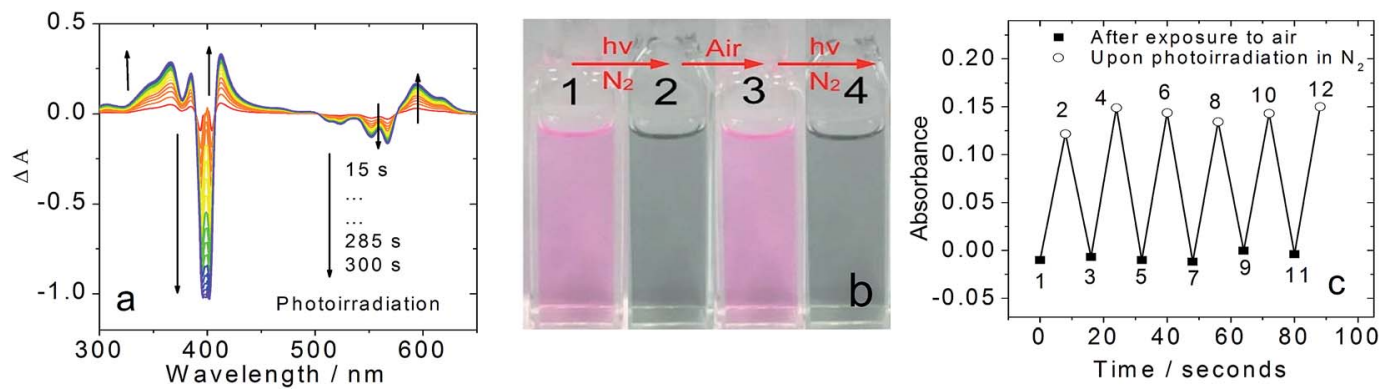

Fig. 7 (a) UV-vis difference absorption spectra of $1 \mathrm{PF}_{2}$ in the presence of $\mathrm{Et}_{3} \mathrm{~N}$ in the deaerated MeCN with white light continuous photoirradiation using a xenon lamp, light power density: $5.2 \mathrm{~mW} \mathrm{~cm}{ }^{-2}$. (b) Photos showing the consecutive color change of the $1 \mathrm{PF}_{2} / \mathrm{Et}_{3} \mathrm{~N}$ mixed solution upon alternating photoirradiation and exposure to air: (1). Without photoirradiation under an air atmosphere; (2) Upon 8 second photoirradiation under a $\mathrm{N}_{2}$ atmosphere; (3) Exposure to air after photoirradiation; (4) Upon another 8 second photoirradiation under a $\mathrm{N}_{2}$ atmosphere. (c) Reversibility of the formation of $1 \mathrm{PF}_{2}{ }^{-}$monitored at the $594 \mathrm{~nm}$ absorption band (after generation of $1 \mathrm{PF}_{2}{ }^{-}$, re-exposure to air will oxidize the radical anion to the neutral form $1 \mathrm{PF}_{2}$ ). Photoirradiation power density is $23 \mathrm{~mW} \mathrm{~cm}^{-2} . c\left[1 \mathrm{PF}_{2}\right]=1 \times 10^{-5} \mathrm{M}$ and $c\left[\mathrm{Et}_{3} \mathrm{~N}\right]=$ $0.25 \mathrm{M}, 20^{\circ} \mathrm{C}$. 
Table 2 Redox potentials of phosphorus corroles

\begin{tabular}{|c|c|c|c|c|c|c|}
\hline & \multicolumn{2}{|c|}{ Ground state redox potentials, $\mathrm{V} v s . \mathrm{Ag} / \mathrm{AgCl}$} & \multirow[b]{2}{*}{$E_{\mathrm{S}}^{a}(\mathrm{eV})$} & \multirow[b]{2}{*}{$E_{\mathrm{T}}^{b}(\mathrm{eV})$} & \multicolumn{2}{|c|}{$\begin{array}{l}\text { Excited state redox potentials, } \mathrm{V} v s \text {. } \\
\mathrm{Ag} / \mathrm{AgCl}\end{array}$} \\
\hline & $E_{1 / 2}^{\mathrm{ox}}\left(\right.$ corrole $^{+} /$corrole $)$ & $E_{1 / 2}^{\text {red }}\left({\left.\text { corrole } / \text { corrole }^{-}\right)}\right.$ & & & $E_{\mathrm{oxd}}^{\mathrm{o}^{*}}$ & $E_{\mathrm{red}}^{\mathrm{o}^{*}}$ \\
\hline $\mathbf{P P F}_{2}$ & 1.34 & -0.90 & 2.15 & $1.57^{c}$ & $-0.81^{d}(-0.23)^{e}$ & $1.25^{d}(0.67)^{e}$ \\
\hline $1 \mathrm{PF}_{2}-\mathrm{I}_{4}$ & 1.34 & -0.74 & 2.07 & $1.56(1.49)^{c}$ & $-0.73^{d}(-0.22)^{e}$ & $1.33^{d}(0.82)^{e}$ \\
\hline $2 \mathbf{P F}_{2}$ & 1.20 & -1.03 & 2.13 & $1.55^{c}$ & $-0.83^{d}(-0.35)^{e}$ & $1.11^{d}(0.52)^{e}$ \\
\hline
\end{tabular}

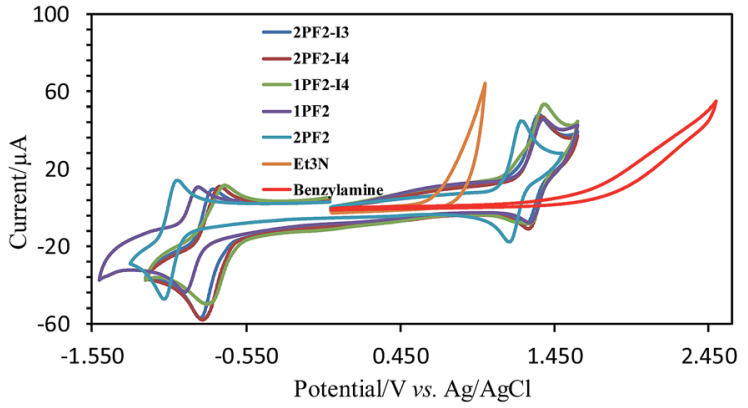

Fig. 9 Cyclic voltammograms of phosphorus corroles, triethylamine $\left(\mathrm{Et}_{3} \mathrm{~N}\right)$, and benzylamine in acetonitrile ( $1 \mathrm{mM}$ substrate, $0.1 \mathrm{M}$ TBAP as the electrolyte, glassy carbon as the working electrode, $\mathrm{Ag} / \mathrm{AgCl}$ as the reference electrode, and $\mathrm{Pt}$ wire as the supporting electrode; scan rate: $100 \mathrm{mV} \mathrm{s}^{-1}$ ).

photocatalyst: (a) production of singlet oxygen $\left({ }^{1} \mathrm{O}_{2}\right)$ that reacts with the benzylamine; ${ }^{64}$ (b) direct electron transfer from the amine to the photoexcited dye. ${ }^{65}$ Porphyrins, porphycences, and mainly the $\mathrm{Ru}(\mathrm{bpy})_{3}\left[\mathrm{PF}_{6}\right]_{2}$ (bpy $=2,2^{\prime}$-bipyridine) or $\operatorname{Ir}(\mathrm{ppy})_{3}$ complex (ppy $=2$-phenylpyridine) were reported as suitable photocatalysts. ${ }^{65-75}$ However, $\mathrm{Ru}(\mathrm{bpy})_{3}\left[\mathrm{PF}_{6}\right]_{2}$ has only very weak absorption in the visible spectral region, and its triplet state lifetime is quite short $\left(1.10 \mu \mathrm{s}\right.$ in $\left.\mathrm{CH}_{3} \mathrm{CN}\right){ }^{.6}$ These photophysical features are not optimal and precious metal complex photosensitizers are also expensive. Our results show that phosphorus corroles, free of any precious or rare elements, are efficient photocatalysts for the Aza Henry reaction (Table 3). With only $1 \mathrm{~mol} \%$ phosphorus corrole, most of the benzylamine was converted with high selectivity to $N$-benzylidenebenzylamine (67-100\%), at RT and after short time visible light irradiation $(1 \mathrm{~h})$. No reaction took place in the absence of oxygen and $\mathbf{2} \mathbf{P F}_{2}$ appeared to be the best photocatalyst among the phosphorus corroles that were tested in this study, despite displaying the lowest reduction potential of its photo-excited triplet state $(0.52 \mathrm{~V})$. This result indicates that the photocatalytic reaction mechanism in our system may be attributed to the involvement of ${ }^{1} \mathrm{O}_{2}$ and not the electron transfer mechanism (Scheme 2) ${ }^{64}$ In fact, a comparison of the oxidation potential of benzylamine and the redox potentials of the phosphorus corroles suggests that all the phosphorus corroles tested in this study cannot photo-oxidize the amine via the electron transfer mechanism. The onset potential for oxidation of benzylamine is $1.62 \mathrm{~V}$, which is much higher than the photoreduction potential of the triplet excited state and even higher than the ground state oxidation potentials of all the phosphorus corroles (Table 2). We hence propose that the oxidation of benzylamine by the phosphorus corroles as photosensitizers occurs via the singlet oxygen mechanism, which is also consistent with the superiority of $\mathbf{2} \mathbf{P F}_{2}$ as its photoexcited state is highest in energy.

\section{Triplet-triplet annihilation upconversion with the phosphorus corroles as triplet photosensitizers}

Considering that the corroles are characterized by strong absorption of visible light and the long-lived triplet excited state, the compounds were tested as triplet photosensitizers

Table 3 Transformation of benzylamine catalyzed by different triplet photosensitizers $^{a}$

\begin{tabular}{llllll}
\hline Entry & Photosensitizer & $T\left({ }^{\circ} \mathrm{C}\right)$ & $T(\mathrm{~h})$ & Conv. $^{b, c}(\%)$ & $\Phi_{\mathrm{UC}}{ }^{d} / \%$ \\
\hline 1 & $\mathbf{1 P F}_{\mathbf{2}}$ & 20 & 1.0 & 87 & 33.6 \\
2 & $\mathbf{1 P F}_{\mathbf{2}}-\mathbf{I}_{\mathbf{4}}$ & 20 & 1.0 & 67 & 24.8 \\
3 & $\mathbf{2}_{\mathbf{2}}$ & 20 & 1.0 & 100 & 38.9 \\
4 & $\mathbf{2}_{\mathbf{2}} \mathbf{P}_{\mathbf{2}}$ & 20 & 1.0 & 75 & 26.4 \\
5 & $\mathbf{2 P F}_{\mathbf{2}}-\mathbf{I}_{\mathbf{4}}$ & 20 & 1.0 & 87 & 34.1 \\
6 & $\mathbf{R u}\left(\mathbf{b p y}_{\mathbf{3}}\left[\mathbf{P F}_{\mathbf{6}}\right]_{\mathbf{2}}\right.$ & 20 & 1.0 & 100 & $-^{e}$
\end{tabular}

${ }^{a}$ Reaction conditions: benzylamine $(0.5 \mathrm{mmol})$, photosensitizers (catalyst, $0.005 \mathrm{mmol}, 1 \mathrm{~mol} \%)$, solvent $(5 \mathrm{~mL})$, under an air atmosphere, $\lambda>380 \mathrm{~nm}\left(20 \mathrm{~mW} \mathrm{~cm}{ }^{-2}\right), 1 \mathrm{~h}, 20{ }^{\circ} \mathrm{C}$, in $\mathrm{MeCN} / \mathrm{CH}_{2} \mathrm{Cl}_{2}$ $(5: 1, \mathrm{v} / \mathrm{v}) .{ }^{b}$ Yield was determined by ${ }^{1} \mathrm{H}$ NMR. The conversion of the reaction was calculated by integrating the singlet peak of the featured proton in the products (at about $4.82 \mathrm{ppm}$ for $-\mathrm{CH}=\mathrm{N}-\mathrm{CH}_{2}-$ ) and that of the corresponding proton in the starting materials (at about $3.86 \mathrm{ppm}$ as the singlet for $\mathrm{H}_{2} \mathrm{~N}-\mathrm{CH}_{2}-$ ). ${ }^{c}$ Reaction was monitored by TLC. Only two spots (one point was attributed to the starting material and the other was attributed to the product) were found (except the photosensitizer), and therefore the selectivity of the photoreaction is good. ${ }^{d}$ TTA upconversion quantum yield with diiodo-distyryl-bodipy as the standard $\left(\Phi_{\mathrm{F}}=0.101\right.$ in DCM). The laser power density is $70.6 \mathrm{~mW} \mathrm{~cm}^{-2}$. ${ }^{e}$ Not measured. 


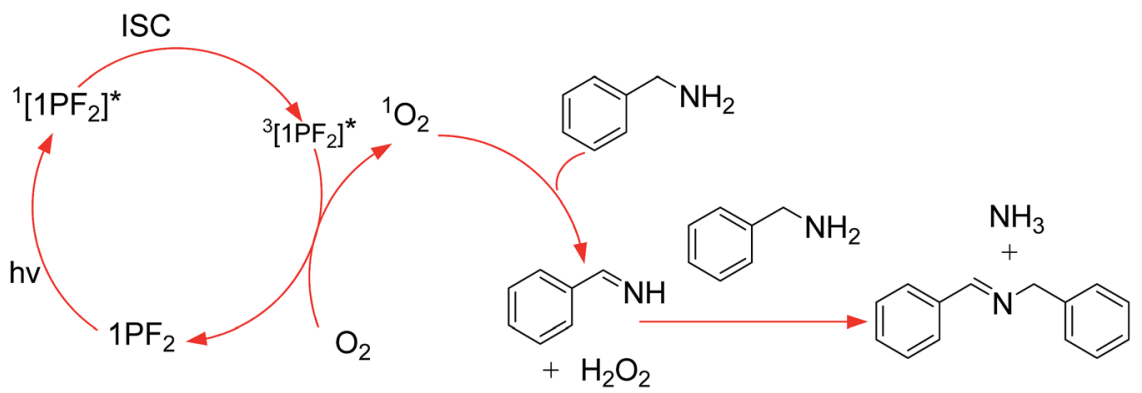

Scheme 2 Proposed reaction mechanism for the photocatalytic aerobatic oxidation of benzylamine with the triplet photosensitizers $1 \mathrm{PF}_{2}$, $1 \mathrm{PF}_{2}-$ $\mathrm{I}_{4}, 2 \mathrm{PF}_{2}, 2 \mathrm{PF}_{2}-\mathrm{I}_{3}$ and $2 \mathrm{PF}_{2}-\mathrm{I}_{4}$

for TTA upconversion (Fig. 10). Nitridoosmium(vi) and oxorhenium(v) corroles were previously reported for TTA upconversion, with SG 5 (diisobutyl 3,9-perylenedicarboxylate) as the triplet acceptor, but the upconversion quantum yields were very low: $0.16 \%-2.0 \% .^{32,46}$ Based on the triplet state energy level of the corroles (approximated as $1.56 \mathrm{eV}$, by the phosphorescence emission of $\left.\mathbf{1 P F}_{2}-\mathbf{I}_{\mathbf{4}}\right)$, perylene was selected as the triplet acceptor and the emitter (with a $\mathrm{T}_{1}$ state energy level of 1.54 eV). ${ }^{77}$ For $\mathbf{1} \mathbf{P F}_{2}-\mathbf{I}_{4}$, no emission was observed upon $589 \mathrm{~nm} \mathrm{cw}$ laser excitation (Fig. 10b). This is due to the weak emission of $\mathbf{1 P F}_{2}-\mathbf{I}_{4}$ (luminescence quantum yield: $0.27 \%$, Table 1 ). In the presence of perylene, however, strong emission was observed in the range of $420-550 \mathrm{~nm}$, which is the characteristic emission profile of perylene. Taking into account that the excitation wavelength is $589 \mathrm{~nm}$, which is insufficient for the direct excitation of perylene, the emission is safely attributed to TTA. The upconversion quantum yield was determined as $24.8 \%$ (Table 3 , note that the factor of 2 was used in the equation). Similarly, upconversion was also observed with $\mathbf{1 P F}_{2}$ as the triplet photosensitizer (Fig. 10a), but its anti-Stoke's shift was much smaller. The visual perception of the upconversion systems is shown in Fig. 11. It is clear that the blue upconverted emission with $\mathbf{1} \mathbf{P F}_{2}-\mathbf{I}_{\mathbf{4}}$ is more significant than that of $\mathbf{1} \mathbf{P F}_{2}$. The highest upconversion quantum yield was observed with $\mathbf{2} \mathbf{P F}_{2}$ (38.9\%)

In order to study the efficient TTA upconversion capability, the upconversion intensity-excitation power relationship was
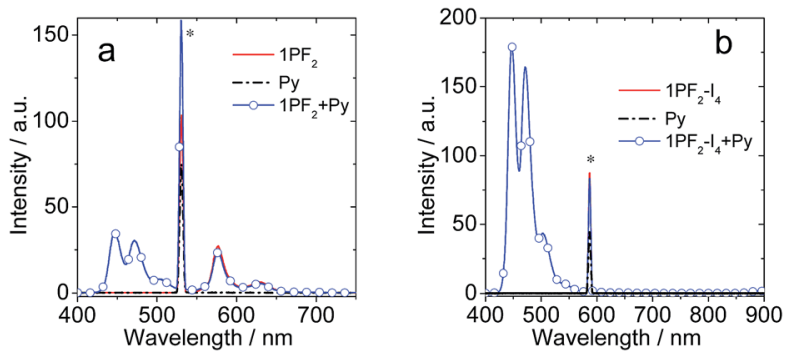

Fig. 10 The upconversion fluorescence spectra of (a) $1 \mathrm{PF}_{2}$ and (b) $1 \mathrm{PF}_{2}-\mathrm{I}_{4}$ as photosensitizers in toluene. Py (perylene) was the acceptor Excitation was done with a continuous laser of $532 \mathrm{~nm}$ for $1 \mathrm{PF}_{2}$ and $589 \mathrm{~nm}$ for $1 \mathrm{PF}_{2}-\mathrm{I}_{4}$ and the power density was $70.6 \mathrm{~mW} \mathrm{~cm}^{-2}$ under a deaerated atmosphere. $c$ (sensitizer) $=2.0 \times 10^{-6} \mathrm{M}$, and $c$ (Py) was $2.4 \times 10^{-5} \mathrm{M}$ and $2.8 \times 10^{-5} \mathrm{M}$, respectively, $20^{\circ} \mathrm{C}$.
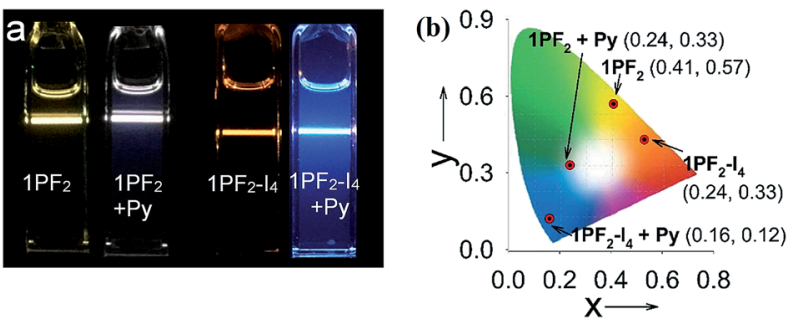

Fig. 11 (a) Photographs of the emission of triplet photosensitizers alone and the upconversion. The $\mathrm{CIE}$ coordinate of (b) the luminescence of the triplet sensitizers $\left(1 \mathrm{PF}_{2}\right.$ and $\left.1 \mathrm{PF}_{2}-\mathrm{I}_{4}\right)$ before and after adding Py. Excited with a continuous laser of $532 \mathrm{~nm}$ for $1 \mathrm{PF}_{2}$ and a $589 \mathrm{~nm}$ laser for $1 \mathrm{PF}_{2}-\mathrm{I}_{4}$. The power density was $4.8 \mathrm{~mW}$. $\mathrm{c}$ (sensitizers) $=2.0 \times 10^{-6} \mathrm{M}$ in deaerated toluene. Py was at $2.4 \times 10^{-5} \mathrm{M}$ and $2.8 \times 10^{-5} \mathrm{M}$ for upconversion, respectively, $20^{\circ} \mathrm{C}$.

investigated (Fig. S43-S47†). A linear relationship, instead of the typical quadratic relationship, was observed. This is indicative of a highly efficient TTA upconversion system, with efficient triplet-triplet-energy-transfer (TTET) ${ }^{78}$

The intermolecular triplet state energy transfer between the phosphorus corrole photosensitizers and the triplet energy acceptor perylene was also studied by nanosecond transient absorption spectroscopy, focusing on the quenched triplet state lifetime in the presence of increasing amounts of perylene (Fig. 12). Analysis of the Stern-Volmer plots provides the SternVolmer quenching constants ( $K_{\mathrm{SV}}$ values), in the range of
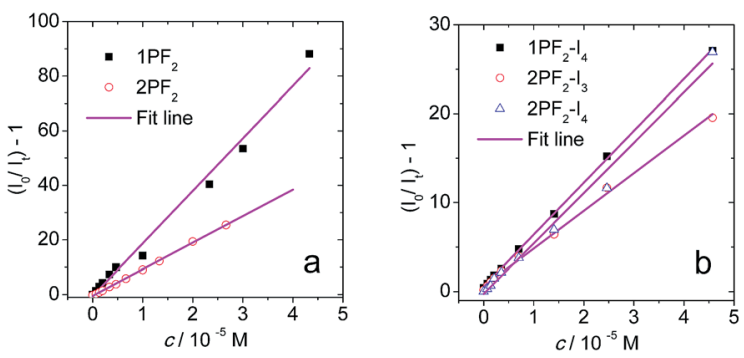

Fig. 12 Stern-Volmer plots based on fluorescence intensityquenching of (a) $1 \mathrm{PF}_{2}$ and $2 \mathrm{PF}_{2}\left(\lambda_{\text {ex }}=532 \mathrm{~nm}\right)$; and phosphorescence intensity-quenching of (b) $1 \mathrm{PF}_{2}-\mathrm{I}_{4}, 2 \mathrm{PF}_{2}-\mathrm{I}_{3}$ and $2 \mathrm{PF}_{2}-\mathrm{I}_{4}\left(\lambda_{\text {ex }}=589 \mathrm{~nm}\right)$, with perylene as the quencher. $c$ [sensitizers] $=2.0 \times 10^{-6} \mathrm{M}$ in toluene, at $20^{\circ} \mathrm{C}$. 
Table 4 Upconversion-related parameters for $1 \mathrm{PF}_{2}, 2 \mathrm{PF}_{2}, 1 \mathrm{PF}_{2}-\mathrm{I}_{4}$, $2 \mathrm{PF}_{2}-\mathrm{I}_{3}$ and $2 \mathrm{PF}_{2}-\mathrm{I}_{4}$, for their utility as photosensitizers ${ }^{a}$

\begin{tabular}{lrcccc}
\hline & $\mathbf{1 P F}_{\mathbf{2}}$ & $\mathbf{1 P F}_{2}-\mathbf{I}_{\mathbf{4}}$ & $\mathbf{2 P F}_{\mathbf{2}}$ & $\mathbf{2 P F}_{\mathbf{2}}-\mathbf{I}_{\mathbf{3}}$ & $\mathbf{2 P F}_{\mathbf{2}}-\mathbf{I}_{\mathbf{4}}$ \\
\hline$K_{\mathrm{SV}}{ }^{b} / 10^{5} \mathrm{M}^{-1}$ & 19.3 & 5.8 & 9.7 & 4.2 & 5.7 \\
$k_{\mathrm{q}}{ }^{c} / 10^{9} \mathbf{M}^{-1} \mathrm{~s}^{-1}$ & 6.2 & 3.3 & 5.1 & 3.3 & 3.1 \\
$R_{\mathrm{q}}{ }^{d} / 10^{-10} \mathrm{~m}$ & 3.7 & 3.7 & 3.7 & 3.7 & 3.7 \\
$D_{\mathrm{q}}{ }^{e} / 10^{-6} \mathrm{~cm}^{2} \mathrm{~s}^{-1}$ & 7.4 & 7.4 & 7.4 & 7.4 & 7.4 \\
$k_{0}^{f} / 10^{9} \mathrm{M}^{-1} \mathrm{~s}^{-1}$ & 8.1 & 8.1 & 8.1 & 8.1 & 8.1 \\
$f_{\mathrm{Q}}{ }^{g} / \%$ & 75.8 & 40.0 & 62.1 & 40.6 & 38.7 \\
$\Phi_{\text {TTET }}{ }^{h} / \%$ & 97.9 & 94.4 & 95.1 & 92.6 & 94.4
\end{tabular}

${ }^{a}$ In deaerated toluene, $c$ (sensitizers) $=2.0 \times 10^{-6} \mathrm{M}, \lambda_{\mathrm{ex}}=532 \mathrm{~nm}$ for $\mathbf{1} \mathbf{P F}_{2}$ and $2 \mathbf{P F}_{2}, \lambda_{\mathrm{ex}}=589 \mathrm{~nm}$ for $\mathbf{1} \mathbf{P F}_{2}-\mathbf{I}_{\mathbf{4}}, \mathbf{2} \mathbf{P F}_{2}-\mathbf{I}_{3}$ and $2 \mathbf{P F}_{2}-\mathbf{I}_{4} \cdot{ }^{b}$ SternVolmer quenching constants. ${ }^{c}$ Bimolecular quenching constants. $K_{\mathrm{SV}}$ $=k_{\mathrm{q}} \tau_{\mathrm{p}} \cdot{ }^{d}$ The radius of the quencher molecules. ${ }^{e}$ Diffusion coefficients. In toluene, $\eta=5.9 \times 10^{-4} \mathrm{~Pa} \mathrm{~s} ; T=293.15 \mathrm{~K} ; R_{\mathrm{f}}\left(\mathbf{1 P F}_{2}\right)=$ $R_{\mathrm{f}}\left(\mathbf{1 P F}_{2}\right)=R_{\mathrm{f}}\left(\mathbf{P P F}_{2}-\mathbf{I}_{4}\right)=R_{\mathrm{f}}\left(2 \mathbf{P F}_{2}-\mathbf{I}_{3}\right)=R_{\mathrm{f}}\left(2 \mathbf{P F}_{2}-\mathbf{I}_{4}\right)=5.01 \times 10^{-10} \mathrm{~m} ;$ $D_{\mathrm{f}}$ is for the energy donor, $D_{\mathrm{f}}=5.54 \times 10^{-6} \mathrm{~cm}^{2} \mathrm{~s}^{-1}$ for all three compounds, $D_{\mathrm{q}}$ is for the quencher molecules. ${ }^{f}$ Diffusion-controlled bimolecular quenching rate constants. ${ }^{g}$ The quenching efficiency. ${ }^{h}$ The bimolecular TTET efficiency $\left(\Phi_{\text {TTET }}\right)$ occurred between perylene and the triplet dyad, $\Phi_{\text {TTET }}=1-\tau / \tau_{0}$, where $\tau_{0}$ and $\tau$ are the lifetimes of the triplet dyad in the absence and presence of perylene, respectively.

4.2-19.3 $\times 10^{5} \mathrm{M}^{-1}$ (Table 4). The bimolecular quenching constants $\left(k_{\mathrm{q}}\right)$ calculated based on the variation of the triplet state lifetimes are in the range of 3.1-6.2 $\times 10^{9} \mathrm{M}^{-1} \mathrm{~s}^{-1}$. As these values are close to the diffusion-controlled bimolecular rate constants $\left(k_{0}\right)$, we conclude that the intermolecular triplettriplet energy transfer is very efficient. We further note that, to the best of our knowledge, this is the first report of TTA upconversion with corroles not chelated by transition metals.

\section{Conclusions}

A series of phosphorus corroles with peripheral fluorinated phenyl moieties were prepared, with focus on those that are also with iodo-substituents on the $\pi$-conjugation core. The photophysical properties were studied by both steady state and timeresolved spectroscopies. The corroles display intense absorption in the visible spectral region (centered at $404 \mathrm{~nm}$ for $\mathbf{1} \mathbf{P F}_{2}$ ), and iodo-substitution on the core induces up to $19 \mathrm{~nm}$ redshifts of the absorption band. Near IR phosphorescence (centered as $796 \mathrm{~nm}$ ) was observed in fluid solution at room temperature for the iodo-substituted derivatives, whereas the regular phosphorus corroles emit only fluorescence. Transient absorption spectroscopy was used for determining photoexcited triplet state formation and lifetimes $\left(\tau_{\mathrm{T}}\right)$, which ranged from $=$ 412 to $179 \mu \mathrm{s}$. Singlet oxygen quantum yields $\left(\Phi_{\Delta}\right)$ of the compounds were elucidated to be in the range of $46-71 \%$, with higher quantum yields for the iodo-containing corroles. Properly tuned photo-excited corroles react with both reductive and oxidative quenchers, as exemplified by their reactions with a frequently used sacrificial electron donor (triethylamine) and the formation of superoxide radical anions $\left(\mathrm{O}_{2}^{-\cdot}\right)$, respectively. They may hence be very useful as photoredox catalysts for many organic transformations. ${ }^{79-81}$ This was exemplified by utilizing the phosphorus corroles as triplet photosensitizers for efficient photocatalytic oxidative coupling of benzylamine (the Aza
Henry reaction). Efficient triplet-triplet annihilation upconversion was observed with the phosphorus corroles as triplet photosensitizers and perylene as the triplet acceptor. The upconversion quantum yield is record high, with up to $\Phi_{\mathrm{UC}}=$ $38.9 \%$ (a factor of 2 was used in the equation) for $\mathbf{2} \mathbf{P F}_{\mathbf{2}}-\mathbf{I}_{\mathbf{4}}$ and an anti-Stokes effect of $0.5 \mathrm{eV}$, an outcome of appropriate adjustment of excited-state lifetimes and redox potentials. This work demonstrates that phosphorus corroles can be developed as a new type of efficient triplet photosensitizers for photocatalytic organic reactions and photon upconversions.

\section{Experimental}

\section{General methods}

All the chemicals used in synthesis were analytically pure and were used as received. $\mathbf{1 P}(\mathbf{O H})_{2}, \mathbf{1 P F}_{2}, \mathbf{2} \mathbf{P F _ { 2 }}, \mathbf{2 P}(\mathbf{O H})_{2}-\mathbf{I}_{3}$, and $\mathbf{2} \mathbf{P}(\mathbf{O H})_{2}-\mathbf{I}_{\mathbf{4}}$ were synthesized as previously reported. ${ }^{41}$ Fluorescence quantum yields were measured in toluene, with $\mathrm{Ru}(\mathrm{bpy})_{3}\left[\mathrm{PF}_{6}\right]_{2}$ in deaerated $\mathrm{CH}_{3} \mathrm{CN}\left(\Phi_{\mathrm{p}}=9.5 \%\right)$ as in ref. 54 . The molecular structures of the corroles are shown in Scheme 1. The fluorescence lifetimes of the compounds were measured with an OB920 luminescence lifetime spectrometer (in TCSPC detection mode. Edinburgh Instrument Ltd., UK). The fluorescence lifetimes were measured with $405 \mathrm{~nm}$ EPL picosecond pulsed laser excitation (pulse width: 51.9 ps, maximum average power: $5 \mathrm{~mW}$ ). The phosphorescence lifetimes were measured with a $\mu$ s flash lamp (maximum average power: $100 \mu \mathrm{W}$ ). Fluorescence and triplet-triplet annihilation (TTA) upconversion spectra were recorded with a RF 5301PC spectrofluorometer (Shimadzu, Japan). ${ }^{1} \mathrm{H}$ and ${ }^{19} \mathrm{~F}$ NMR spectra were recorded using a Bruker Advance III $400 \mathrm{MHz}$ spectrometer (operating at 400.4 MHz for ${ }^{1} \mathrm{H}$ and at 376.7 $\mathrm{MHz}$ for ${ }^{19} \mathrm{~F}$ ). Chemical shifts are reported in ppm relative to the residual hydrogen atoms in the $\mathrm{CDCl}_{3}$ solvent $(\delta=7.26)$, and relative to $\mathrm{CFCl}_{3}(\delta=0.00)$ in the ${ }^{19} \mathrm{~F}$ NMR spectra. Mass spectra for the compounds were recorded on a Bruker MaXis Impact mass spectrometer, using an APCI (atmospheric pressure chemical ionization) direct probe in either positive or negative mode.

\section{Synthesis and characterization}

Synthesis of $2 \mathbf{P F}_{2}-\mathbf{I}_{3}$. A sample of $2 \mathbf{P}(\mathbf{O H})_{2}-\mathbf{I}_{3}(20 \mathrm{mg}, 18.2$ $\mu \mathrm{mol})$ was dissolved in $\mathrm{CH}_{2} \mathrm{Cl}_{2}(5 \mathrm{~mL})$ in a small plastic flask. $2 \mathrm{~mL}$ of $40 \%$ hydrofluoric acid (caution! HF should be handled with extreme care. It is a highly corrosive inorganic acid and can cause deep tissue damage) was added and the mixture was stirred overnight. The $\mathrm{CH}_{2} \mathrm{Cl}_{2}$ solution was separated and washed twice with distilled water, and the organic layer was dried over anhydrous sodium sulfate and evaporated. The purple solid material was crystalized in $n$-hexane/ $\mathrm{CH}_{2} \mathrm{Cl}_{2}$ (1: 1 , $\mathrm{v} / \mathrm{v}$ ) to afford pure $\mathbf{2 P F}_{2}-\mathbf{I}_{3}$ in $92 \%$ yield $(18 \mathrm{mg}, 16.7 \mu \mathrm{mol}) .{ }^{1} \mathrm{H}$ NMR (400.4 MHz, $\left.\mathrm{CDCl}_{3}\right): \delta=9.99($ broad s, $1 \mathrm{H}), 8.89($ broad s, $2 \mathrm{H}), 8.69($ broad $\mathrm{s}, 2 \mathrm{H}), 7.75$ (unresolved $\mathrm{m}, 3 \mathrm{H}), 7.30(\mathrm{t}, J=$ $6.80 \mathrm{~Hz}, 6 \mathrm{H}) .{ }^{19} \mathrm{~F}$ NMR $\left(376.75 \mathrm{MHz}, \mathrm{CDCl}_{3}\right):-36.90(\mathrm{~d}, J=$ $829.23 \mathrm{~Hz}, 2 \mathrm{~F}),-108.01$ (unresolved t, 2F), -108.08 (broad s, 4F). ${ }^{31} \mathrm{P}$ NMR (162 MHz, $\left.\mathrm{CDCl}_{3}\right) \delta=-180.3$ (t, $\left.J=828 \mathrm{~Hz}\right) \cdot{ }^{13} \mathrm{C}$ $\operatorname{NMR}\left(\mathrm{CDCl}_{3}\right) \delta=164.11,161.69,140.61,137.86,132.18,131.69$, 
124.50, 115.55, 114.47, 111.98, 111.79, 111.74, 101.11. UV-vis (toluene) $\lambda_{\max }(\varepsilon)\left[\mathrm{nm}\left(\times 10^{5} \mathrm{~cm}^{-1} \mathrm{M}^{-1}\right)\right]: 415$ (2.88), $570(0.42)$, 587 (0.61). HR-MS (APCI ${ }^{+}$) for $\mathrm{C}_{37} \mathrm{H}_{14} \mathrm{~N}_{4} \mathrm{~F}_{8} \mathrm{I}_{3} \mathrm{P}: \mathrm{m} / z=1077.7957$ (calculated), 1077.8015 (observed).

Synthesis of $2 \mathbf{P F}_{2}-\mathbf{I}_{4}$. The procedure for axial ligand substitution was performed on complex $2 \mathbf{P}(\mathbf{O H})_{2}-\mathbf{I}_{4}$, by the same method and for the same amounts as for complex $2 \mathbf{P}(\mathbf{O H})_{2}-\mathbf{I}_{3}$. $17 \mathrm{mg}$ (85\% yield, $16.7 \mu \mathrm{mol})$ was obtained after crystallization from $n$-hexane $/ \mathrm{CH}_{2} \mathrm{Cl}_{2}=1: 1 .{ }^{1} \mathrm{H} \mathrm{NMR}\left(400.4 \mathrm{MHz}, \mathrm{CDCl}_{3}\right): \delta=$ $8.93(\mathrm{t}, J=4.8 \mathrm{~Hz}, 2 \mathrm{H}), 8.71(\mathrm{t}, J=4.8 \mathrm{~Hz}, 2 \mathrm{H}), 7.75$ (unresolved $\mathrm{m}, 3 \mathrm{H}$ ), 7.30 (unresolved $\mathrm{m}, 6 \mathrm{H}) .{ }^{19} \mathrm{~F} \mathrm{NMR}\left(376.75 \mathrm{MHz}, \mathrm{CDCl}_{3}\right.$ ): $-37.52(\mathrm{~d}, J=832.61 \mathrm{~Hz}, 2 \mathrm{~F}$ ), -108.01 (unresolved $\mathrm{m}, 4 \mathrm{~F}$ ), -108.14 (unresolved m, 2F). ${ }^{31} \mathrm{P}$ NMR (162 $\left.\mathrm{MHz}, \mathrm{CDCl}_{3}\right) \delta=$ -181.9 (t, $J=832 \mathrm{~Hz}) .{ }^{13} \mathrm{C}$ NMR $\left(\mathrm{CDCl}_{3}\right) \delta=161.50,132.18$, 131.68, 128.00, 127.92, 124.92, 124.155, 124.07, 112.08, 111.83. UV-vis (toluene) $\lambda_{\max }(\varepsilon)\left[\mathrm{nm}\left(\times 10^{5} \mathrm{~cm}^{-1} \mathrm{M}^{-1}\right)\right]: 417$ (3.06), 570 (0.42), 576 (0.61). HR-MS $\left(\mathrm{APCI}^{+}\right.$) for $\mathrm{C}_{37} \mathrm{H}_{13} \mathrm{~N}_{4} \mathrm{~F}_{8} \mathrm{I}_{4} \mathrm{P}: \mathrm{m} / \mathrm{z}=$ 1203.6924 (calculated), 1203.6954 (observed).

X-ray quality crystals of $\mathbf{2} \mathbf{P F}_{2}-\mathbf{I}_{\mathbf{4}}$ were obtained from recrystallization from a mixture of $\mathrm{CH}_{2} \mathrm{Cl}_{2}: n$-hexane $(1: 1, \mathrm{v} / \mathrm{v})$ solution. Crystal data for $\mathrm{C}_{38} \mathrm{H}_{15} \mathrm{Cl}_{2} \mathrm{~F}_{8} \mathrm{I}_{4} \mathrm{~N}_{4} \mathrm{P}\left(M=1289.01 \mathrm{~g} \mathrm{~mol}^{-1}\right)$ : monoclinic, space group $P 2_{1} / c$ (no. 14), $a=21.925(2) \AA, b=$ $13.1020(11) \AA, c=13.146(3) \AA, \beta=97.96(5)^{\circ}, V=3740.0(11) \AA^{3}$, $Z=4, T=200.15 \mathrm{~K}, \mu(\mathrm{MoK} \alpha)=3.596 \mathrm{~mm}^{-1}$, Dcalc $=$ $2.289 \mathrm{~g} \mathrm{~cm}{ }^{-3}, 6114$ reflections measured $\left(3.752^{\circ} \leq 2 \Theta \leq\right.$ $\left.49.058^{\circ}\right), 6114$ unique $\left(R_{\text {int }}=0.0650, R_{\text {sigma }}=0.0384\right)$ which were used in all calculations. The final $R_{1}$ was $0.0569(I>2 \sigma(I))$ and $w R_{2}$ was 0.1438 (all data). CCDC 1888513. $\dagger$

Synthesis of $\mathbf{1 P}(\mathbf{O H})_{2}-\mathbf{I}_{4}$. A sample of $\mathbf{1 P}(\mathbf{O H})_{2}(40 \mathrm{mg}, 46.6$ $\mu \mathrm{mol}), 50$ eq. of $N$-iodosuccinimide (NIS, $524 \mathrm{mg}$ ), and TFA (200 $\mu \mathrm{L})$ were dissolved in acetonitrile $(10 \mathrm{~mL})$. The solution was stirred for $4 \mathrm{~h}$ at room temperature in the dark. The reaction mixture was diluted with $\mathrm{CH}_{2} \mathrm{Cl}_{2}(40 \mathrm{~mL})$, washed with distilled water $(50 \mathrm{~mL})$, dried over anhydrous sodium sulfate, and evaporated. The reaction products were chromatographed on silica gel by using hexanes/ethyl acetate $(100: 5, \mathrm{v} / \mathrm{v})$ as the eluent. The product was further purified by silica gel 60 preparative thin-layer chromatography (PTLC) with $n$-hexane/ ethyl acetate $(100: 3, \mathrm{v} / \mathrm{v})$ as the eluent. The product was eluted as the third fraction with purple color (20 mg, 32\% yield). ${ }^{1} \mathrm{H} \mathrm{NMR}\left(400.4 \mathrm{MHz}, \mathrm{CDCl}_{3}\right): \delta=8.80(\mathrm{dd}, J=4.8,3.2 \mathrm{~Hz}, 2 \mathrm{H})$, $8.62(\mathrm{dd}, J=4.8,3.2 \mathrm{~Hz}, 2 \mathrm{H}),-4.11$ (d, $7.6 \mathrm{~Hz}, 2 \mathrm{H}) .{ }^{19} \mathrm{~F}$ NMR (376.75 MHz, $\left.\mathrm{CDCl}_{3}\right):-136.10(\mathrm{dd}, J=23.0 \mathrm{~Hz}, 7.5 \mathrm{~Hz}, 4 \mathrm{~F}$; ortho$\mathrm{F}),-136.33(\mathrm{dd}, J=23.0,7.5 \mathrm{~Hz}, 2 \mathrm{~F}$; ortho-F), $-150.68(\mathrm{t}, J=$ $21.1 \mathrm{~Hz}, 1 \mathrm{~F} ;$ para $-\mathrm{F}),-150.94(\mathrm{t}, J=21.5,2 \mathrm{~F} ;$ para $-\mathrm{F}),-160.48$ (m, 2F; meta-F), -161.46 (m, 4F; meta-F). ${ }^{31} \mathrm{P}$ NMR $(162 \mathrm{MHz}$, $\left.\mathrm{CDCl}_{3}\right) \delta=-188.0(\mathrm{~s})$. UV-vis (toluene) $\lambda_{\max }(\varepsilon)\left[\mathrm{nm}\left(\times 10^{5} \mathrm{~cm}^{-1}\right.\right.$ $\left.\mathrm{M}^{-1}\right)$ ]: 428 (2.6), 551 (0.17), 596 (0.60). HR-MS (APCI ${ }^{+}$) for $\mathrm{C}_{37^{-}}$ $\mathrm{H}_{6} \mathrm{~F}_{15} \mathrm{~N}_{4} \mathrm{I}_{4} \mathrm{PO}_{2}: m / z=1361.6162$ (calculated), 1361.6148 (observed).

Synthesis of $\mathbf{1 P F}_{2}-\mathbf{I}_{4}$. The procedure for axial ligand substitution was performed on complex $\mathbf{1 P}(\mathbf{O H})_{2}-\mathbf{I}_{4}$, by the same method as for complex $2 \mathbf{P}(\mathbf{O H})_{2}-\mathbf{I}_{3} .18 \mathrm{mg}(90 \%$ yield, $13.2 \mu \mathrm{mol})$ was obtained after crystallization from $n$-hexane $/ \mathrm{CH}_{2} \mathrm{Cl}_{2}(1: 1$, v/v). ${ }^{1} \mathrm{H}$ NMR (400.4 MHz, $\left.\mathrm{CDCl}_{3}\right): \delta=8.98($ broad s, $2 \mathrm{H}), 8.78$ (broad s, 2H). ${ }^{19} \mathrm{~F}$ NMR (376.75 $\left.\mathrm{MHz}, \mathrm{CDCl}_{3}\right):-27.20$ (d, $J=$ $818.19 \mathrm{~Hz}, 2 \mathrm{~F}$ ), -135.72 (unresolved $\mathrm{m}, 2 \mathrm{~F}$; ortho-F), -136.47 (unresolved $\mathrm{m}, 4 \mathrm{~F}$; ortho-F), $-150.41(\mathrm{t}, J=21.80 \mathrm{~Hz}, 1 \mathrm{~F} ;$ para-F), $-150.92(\mathrm{t}, J=21.80 \mathrm{~Hz}, 2 \mathrm{~F} ;$ para $-\mathrm{F}),-160.75$ (m, 2F; meta-F), $-160.92\left(\mathrm{~m}, 4 \mathrm{~F}\right.$; meta-F). ${ }^{31} \mathrm{P}$ NMR $\left(162 \mathrm{MHz}, \mathrm{CDCl}_{3}\right) \delta=-183.5$ $(\mathrm{t}, J=819 \mathrm{~Hz}) .{ }^{13} \mathrm{C} \mathrm{NMR}\left(\mathrm{CDCl}_{3}\right) \delta=139.00,136.53,129.05$, 126.70, 126.62, 126.55, 126.44, 123.15, 123.07, 100.23, 100.17, 95.92. UV-vis (toluene) $\lambda_{\max }(\varepsilon)\left[\mathrm{nm}\left(\times 10^{5} \mathrm{~cm}^{-1} \mathrm{M}^{-1}\right)\right]: 423(2.8)$, 544 (0.15), 589 (0.62). HR-MS (APCI ${ }^{+}$) for $\mathrm{C}_{37} \mathrm{H}_{4} \mathrm{~F}_{17} \mathrm{~N}_{4} \mathrm{I}_{4} \mathrm{P}-2 \mathrm{H}^{+}: \mathrm{m} /$ $z=1363.5919$ (calculated), 1363.6068 (observed).

X-ray quality crystals of $\mathbf{1} \mathbf{P F}_{2}-\mathbf{I}_{\mathbf{4}}$ were obtained from recrystallization from a mixture of $\mathrm{CH}_{2} \mathrm{Cl}_{2}: n$-hexane $(1: 1, \mathrm{v} / \mathrm{v})$ solution. Crystal data for $\mathrm{C}_{39} \mathrm{H}_{4} \mathrm{Cl}_{4} \mathrm{~F}_{17} \mathrm{I}_{4} \mathrm{~N}_{4} \mathrm{P}\left(M=1531.83 \mathrm{~g} \mathrm{~mol}^{-1}\right)$ : monoclinic, space group $P 21 / m$ (no. 11), $a=17.2430$ (13) $\AA$, $b=$ $7.806(5) \AA, c=17.503(3) \AA, \beta=110.42(3)^{\circ}, V=2207.9(15) \AA^{3}, Z=$ $2, T=200.15 \mathrm{~K}, \mu($ MoK $\alpha)=3.211 \mathrm{~mm}^{-1}$, Dcalc $=2.304 \mathrm{~g} \mathrm{~cm}^{-3}$, 3932 reflections measured $\left(4.11^{\circ} \leq 2 \Theta \leq 49.42^{\circ}\right)$, 3932 unique $\left(R_{\text {int }}=0.0770, R_{\text {sigma }}=0.0485\right)$ which were used in all calculations. The final $R_{1}$ was $0.1059(I>2 \sigma(I))$ and $w R_{2}$ was 0.2462 (all data). CCDC 1888512. $\dagger$

Crystal structure determination. The single-crystal material was immersed in Paratone- $\mathrm{N}$ oil and was quickly fished with a glass rod and mounted on a Nonius Kappa CCD diffractometer under a cold stream of nitrogen at $200 \mathrm{~K}$. Using Olex $2,{ }^{82}$ the structure was solved with the SIR2004 (ref. 83) structure solution program using Direct Methods and refined with the ShelXL ${ }^{84}$ refinement package using least squares minimization. The software Mercury 3.10.1 was used for molecular graphics.

Electrochemistry. The cyclic voltammograms were obtained utilizing a PlamStat3+ connected to a personal computer using PSTrace 5.5 software. A three-electrode system was used consisting of a mini glassy carbon electrode (diameter of the active zone: $2.8 \mathrm{~mm}$; Metrohm) as a working electrode, a platinum wire as a counter electrode, and an $\mathrm{Ag} / \mathrm{AgCl}$ electrode as a reference electrode. The $\mathrm{CV}$ measurements were performed in acetonitrile solutions (HPLC grade), $0.1 \mathrm{M}$ tetrabutylammonium perchlorate (TBAP, Fluka, recrystallized twice in methanol), and $1 \mathrm{mM}$ substrate at ambient temperature with $100 \mathrm{mV}$ $\mathrm{s}^{-1}$ scan rates. The $E_{1 / 2}$ value for the ferrocene/ferrocenium $(\mathrm{Fc} /$ $\mathrm{Fc}^{+}$) couple under these conditions was $0.42 \mathrm{~V}$.

Singlet oxygen quantum yield $\left(\Phi_{\Delta}\right)$. 1,3-Diphenylisobenzofuran (DPBF) was used as the ${ }^{1} \mathrm{O}_{2}$ scavenger (Fig. S37†). The ${ }^{1} \mathrm{O}_{2}$ production was monitored by following the absorbance of DPBF at $414 \mathrm{~nm}$ upon photo-irradiation of the photosensitizer/DPBF mixed solution. To determine the singlet oxygen quantum yield $\left(\Phi_{\Delta}\right)$, a relative method was used according to eqn (1):

$$
\Phi_{\mathrm{sam}}=\Phi_{\mathrm{std}}\left(\frac{1-10^{-A_{\mathrm{std}}}}{1-10^{-A_{\mathrm{sam}}}}\right)\left(\frac{m_{\mathrm{sam}}}{m_{\mathrm{std}}}\right)\left(\frac{\eta_{\mathrm{sam}}}{\eta_{\mathrm{std}}}\right)^{2}
$$

where 'sam' and 'std' represent the sample and the standard. $\Phi$, $A, m$ and $\eta$ represent the singlet oxygen quantum yield, the absorbance at the excitation wavelength, the slope of the absorbance of DPBF changing over time, and the refractive index of the solvent used for measurement, respectively. Optically matched solutions were used (the solutions of the sample and the standard give the same absorbance at the excitation wavelength). Singlet oxygen quantum yields $\left(\Phi_{\Delta}\right)$ were 
measured in toluene. The excitation wavelength was $573 \mathrm{~nm}(A$ $=0.222)$ for $1 \mathbf{P F}_{2}, 576 \mathrm{~nm}(A=0.218)$ for $2 \mathbf{P F}_{2}$, and $589 \mathrm{~nm}(A=$ $0.203)$ for the other compounds. The monochromatic light source includes a xenon lamp and a monochromator. Methylene blue (MB) was used as the standard $\left(\Phi_{\Delta}=0.57\right.$ in DCM).

Nanosecond transient absorption spectroscopy. The nanosecond transient absorption spectra were obtained with a LP980-K Laser Flash Photolysis Spectrometer (kinetic mode, Edinburgh Instruments, UK). The analogue signal was digitized with a Tektronix TDS 3012C oscilloscope. The samples were purged with $\mathrm{N}_{2}$ for 15 min and excited with a nanosecond pulsed laser (Opolette ${ }^{\mathrm{TM}}$, the wavelength is tunable in the range of 210-2400 $\mathrm{nm}$. OPOTEK, USA). The raw data were analyzed by using LP900 software.

The general procedure for transformation of benzylamine catalyzed by different triplet photosensitizers. The mixture of photosensitizer $(1 \mathrm{~mol} \%)$ and benzylamine $(0.5 \mathrm{mmol})$ in $\mathrm{CH}_{3} \mathrm{CN}(5 \mathrm{~mL})$ was stirred at room temperature (RT) under an air atmosphere. The solution was irradiated using a $35 \mathrm{~W}$ xenon lamp through a cut off filter $\left(0.72 \mathrm{M} \mathrm{NaNO}_{2}\right.$ aqueous solution, which is transparent for light $>380 \mathrm{~nm}$ ). Thin layer chromatography (TLC) was used to monitor the progress of the reaction. After completion of the reaction, the solvent was evaporated under reduced pressure. The conversion of the photoreactions was determined by ${ }^{1} \mathrm{H}$ NMR: calculated by integrating the singlet peak of the unique proton in the product (at about $4.82 \mathrm{ppm}$ for $-\mathrm{CH}=\mathrm{N}-\mathrm{CH}_{2}{ }^{-}$) relative to that of the corresponding proton in the starting materials (singlet at 3.86 ppm for $\mathrm{H}_{2} \mathrm{~N}-\mathrm{CH}_{2}-$ ).

Photoreduction of the corroles to produce radical anions. UV-vis difference absorption spectra of the corroles were recorded in the presence of $\mathrm{Et}_{3} \mathrm{~N}$ in deaerated $\mathrm{MeCN}$ with white light photoirradiation using a xenon lamp. $\mathrm{Et}_{3} \mathrm{~N}$ was used as the sacrificial electron donor and corrole was used as the electron acceptor. Photos were taken to show the color change using a digital camera.

Triplet-triplet annihilation upconversion. A $532 \mathrm{~nm}$ and $589 \mathrm{~nm}$ continuous wave (cw) diode-pumped solid state laser was used as the excitation source for the upconversion. The mixed solution of the triplet photosensitizers and the triplet acceptors was degassed with $\mathrm{N}_{2}$ for at least 15 min before the upconversion experiments. The upconverted fluorescence was recorded with a RF 5301PC spectrofluorometer. In order to depress the laser scattering in the sample chamber of the spectrometer, a small black box was put behind the cuvette as the beam dump to trap the transmitted laser. The upconversion quantum yields $\left(\Phi_{\mathrm{UC}}\right)$ of the corroles in toluene were determined, relative to diiodo-distyryl-bodipy as the standard: $\Phi_{\mathrm{F}}=$ 0.101 in DCM. Plots of UC intensity vs. power density, in the range of $30-900 \mathrm{~mW} \mathrm{~cm} \mathrm{~cm}^{-2}$, were linear with unity slopes (Fig. S43-S47 $\dagger$ ). The upconversion quantum yields were calculated with the following equation (eqn (2)), where $\Phi, A, I$ and $\eta$ represent the quantum yield, absorbance, integrated photoluminescence intensity and refractive index, respectively. Symbols with 'std' and 'sam' present the corresponding parameter for the standard and sample (eqn (2)). Note a factor of 2 was used in the equation. ${ }^{2}$

$$
\Phi_{\mathrm{UC}}=2 \Phi_{\text {std }}\left(\frac{1-10^{-A_{\text {std }}}}{1-10^{-A_{\text {sam }}}}\right)\left(\frac{m_{\text {sam }}}{m_{\text {std }}}\right)\left(\frac{\eta_{\text {sam }}}{\eta_{\text {std }}}\right)^{2}
$$

Theoretical computations. Density Functional Theory (DFT) and Time-dependent Density Functional Theory (TD-DFT) were used for geometry optimization and energy calculation of all the compounds in a vacuum. All the calculations were performed with the Gaussian 16 program. The geometry optimization of the ground state and the excited state was conducted at the B3LYP/6-31G(d) level for non-iodo-substituted compounds and the B3LYP/GENECP level for iodo-substituted compounds and frequency calculations guarantee that the optimal structures are valid. Vertical excitation energies of singlet and triplet states were calculated at the B3LYP/6-31G(d) level for non-iodosubstituted compounds and the B3LYP/GENECP level for iodo-substituted compounds. The Gaussian 09W program package was used for the calculations. ${ }^{85}$

\section{Conflicts of interest}

There are no conflicts to declare.

\section{Acknowledgements}

ZG and JZ acknowledge the ISF/NSF Israel-China co-funding project (21761142005) for financial support. JZ also thanks the NSFC (21673031, 2181101275 and 21421005), the Fundamental Research Funds for the Central Universities (DUT16TD25, DUT15ZD224, and DUT2016TB12) and the State Key Laboratory of Fine Chemicals (ZYTS201801) for financial support.

\section{Notes and references}

1 P. Ceroni, Chem.-Eur. J., 2011, 17, 9560-9564.

2 T. N. Singh-Rachford and F. N. Castellano, Coord. Chem. Rev., 2010, 254, 2560-2573.

3 Y. Y. Cheng, B. Fückel, R. W. MacQueen, T. Khoury, R. G. C. R. Clady, T. F. Schulze, N. J. Ekins-Daukes, M. J. Crossley, B. Stannowski, K. Lips and T. W. Schmidt, Energy Environ. Sci., 2012, 5, 6953-6959.

4 J. Liu, Y. Liu, Q. Liu, C. Li, L. Sun and F. Li, J. Am. Chem. Soc., 2011, 133, 15276-15279.

5 L. Xiong, Z. Chen, Q. Tian, T. Cao, C. Xu and F. Li, Anal. Chem., 2009, 81, 8687-8694.

6 H. M. Kim and B. R. Cho, Acc. Chem. Res., 2009, 42, 863-872. 7 C. J. Fahrni, in Reviews in Fluorescence 2007, Springer New York, New York, NY, 2009, pp. 249-269.

8 Q. Liu, T. Yang, W. Feng and F. Li, J. Am. Chem. Soc., 2012, 134, 5390-5397.

9 S. H. C. Askes and S. Bonnet, Nat. Rev. Chem., 2018, 2, 437452.

10 B. D. Ravetz, A. B. Pun, E. M. Churchill, D. N. Congreve, T. Rovis and L. M. Campos, Nature, 2019, 565, 343-346.

11 J. Zhao, S. Ji and H. Guo, RSC Adv., 2011, 1, 937-950.

12 S. Ji, W. Wu, W. Wu, H. Guo and J. Zhao, Angew. Chem., Int. Ed., 2011, 50, 1626-1629. 
13 Q. Yan, R. Zhou, C. Fu, H. Zhang, Y. Yin and J. Yuan, Angew. Chem., Int. Ed., 2011, 50, 4923-4927.

14 S. Guo, W. Wu, H. Guo and J. Zhao, J. Org. Chem., 2012, 77, 3933-3943.

15 C. Kerzig and O. S. Wenger, Chem. Sci., 2018, 9, 6670-6678. 16 F. Auzel, Chem. Rev., 2004, 104, 139-174.

17 M. Haase and H. Schäfer, Angew. Chem., Int. Ed., 2011, 50, 5808-5829.

18 G. Bergamini, P. Ceroni, P. Fabbrizi and S. Cicchi, Chem. Commun., 2011, 47, 12780-12782.

19 W. Wu, H. Guo, W. Wu, S. Ji and J. Zhao, J. Org. Chem., 2011, 76, 7056-7064.

20 Y. Shang, S. Hao, C. Yang and G. Chen, Nanomaterials, 2015, 5, 1782-1809.

21 M. González-Béjar, L. Francés-Soriano and J. Pérez-Prieto, Frontiers in Bioengineering and Biotechnology, 2016, 4, 47.

22 W. Wu, J. Zhao, J. Sun and S. Guo, J. Org. Chem., 2012, 77, 5305-5312.

23 P. Yang, W. Wu, J. Zhao, D. Huang and X. Yi, J. Mater. Chem., 2012, 22, 20273-20283.

24 C. A. Parker and J. Bowen Edmund, Proc. R. Soc. London, Ser. A, 1963, 276, 125-135.

25 C. A. Parker and C. G. Hatchard, Proc. Chem. Soc., 1962, 386387.

26 C. Ye, L. Zhou, X. Wang and Z. Liang, Phys. Chem. Chem. Phys., 2016, 18, 10818-10835.

27 J. Peng, X. Guo, X. Jiang, D. Zhao and Y. Ma, Chem. Sci., 2016, 7, 1233-1237.

28 S. Baluschev, V. Yakutkin, T. Miteva, Y. Avlasevich, S. Chernov, S. Aleshchenkov, G. Nelles, A. Cheprakov, A. Yasuda, K. Müllen and G. Wegner, Angew. Chem., Int. Ed., 2007, 46, 7693-7696.

29 R. R. Islangulov, D. V. Kozlov and F. N. Castellano, Chem. Commun., 2005, 3776-3778.

30 H.-C. Chen, C.-Y. Hung, K.-H. Wang, H.-L. Chen, W. S. Fann, F.-C. Chien, P. Chen, T. J. Chow, C.-P. Hsu and S.-S. Sun, Chem. Commun., 2009, 4064-4066.

31 T. N. Singh-Rachford and F. N. Castellano, J. Phys. Chem. A, 2009, 113, 5912-5917.

32 S. M. Borisov, A. Alemayehu and A. Ghosh, J. Mater. Chem. C, 2016, 4, 5822-5828.

33 J. H. Palmer, A. C. Durrell, Z. Gross, J. R. Winkler and H. B. Gray, J. Am. Chem. Soc., 2010, 132, 9230-9231.

34 A. B. Alemayehu, N. U. Day, T. Mani, A. B. Rudine, K. E. Thomas, O. A. Gederaas, S. A. Vinogradov, C. C. Wamser and A. Ghosh, ACS Appl. Mater. Interfaces, 2016, 8, 18935-18942.

35 C. M. Lemon, D. C. Powers, P. J. Brothers and D. G. Nocera, Inorg. Chem., 2017, 56, 10991-10997.

36 M. Soll, K. Sudhakar, N. Fridman, A. Müller, B. Röder and Z. Gross, Org. Lett., 2016, 18, 5840-5843.

37 R. Orłowski, D. Gryko and D. T. Gryko, Chem. Rev., 2017, 117, 3102-3137.

38 X. Miao, W. Hu, T. He, H. Tao, Q. Wang, R. Chen, L. Jin, H. Zhao, X. Lu, Q. Fan and W. Huang, Chem. Sci., 2019, 10, 3096-3102.
39 E. l. G. Azenha, A. C. Serra, M. Pineiro, M. M. Pereira, J. Seixas de Melo, L. G. Arnaut, S. J. Formosinho and A. M. d. A. Rocha Gonsalves, Chem. Phys., 2002, 280, 177190.

40 J. Vestfrid, I. Goldberg and Z. Gross, Inorg. Chem., 2014, 53, 10536-10542.

$41 \mathrm{~J}$. Vestfrid, R. Kothari, A. Kostenko, I. Goldberg, B. Tumanskii and Z. Gross, Inorg. Chem., 2016, 55, 60616067.

42 X. Liang, J. Mack, L.-M. Zheng, Z. Shen and N. Kobayashi, Inorg. Chem., 2014, 53, 2797-2802.

43 Z. Zhang, H.-H. Wang, H.-J. Yu, Y.-Z. Xiong, H.-T. Zhang, L.-N. Ji and H.-Y. Liu, Dalton Trans., 2017, 46, 94819490.

44 F. Wu, J. Liu, P. Mishra, T. Komeda, J. Mack, Y. Chang, N. Kobayashi and Z. Shen, Nat. Commun., 2015, 6, 7547.

45 B. Brizet, N. Desbois, A. Bonnot, A. Langlois, A. Dubois, J.-M. Barbe, C. P. Gros, C. Goze, F. Denat and P. D. Harvey, Inorg. Chem., 2014, 53, 3392-3403.

46 S. M. Borisov, R. F. Einrem, A. B. Alemayehu and A. Ghosh, Photochem. Photobiol. Sci., 2019, 18, 1166-1170.

47 A. Ghosh and M. Ravikanth, Chem.-Eur. J., 2012, 18, 63866396.

48 M. L. Naitana, S. Nardis, G. Pomarico, M. Raggio, F. Caroleo, D. O. Cicero, S. Lentini, L. Prodi, D. Genovese, S. Mitta, A. Sgarlata, M. Fanfoni, L. Persichetti and R. Paolesse, Chem.-Eur. J., 2017, 23, 905-916.

49 X. Zhan, P. Teplitzky, Y. Diskin-Posner, M. Sundararajan, Z. Ullah, Q.-C. Chen, L. J. W. Shimon, I. Saltsman, A. Mahammed, M. Kosa, M.-H. Baik, D. G. Churchill and Z. Gross, Inorg. Chem., 2019, 58, 6184-6198.

50 V. N. Knyukshto, T. H. Ngo, W. Dehaen, W. Maes and M. M. Kruk, RSC Adv., 2016, 6, 43911-43915.

51 E. Pomarico, P. Pospíšil, M. E. F. Bouduban, J. Vestfrid, Z. Gross, S. Záliš, M. Chergui and A. Vlček, J. Phys. Chem. A, 2018, 122, 7256-7266.

52 T. Stensitzki, Y. Yang, A. Berg, A. Mahammed, Z. Gross and K. Heyne, Struct. Dyn., 2016, 3, 043210.

53 C. Zahn, T. Stensitzki, M. Gerecke, A. Berg, A. Mahammed, Z. Gross and K. Heyne, Molecules, 2017, 22, 1174.

54 H. Ishida, S. Tobita, Y. Hasegawa, R. Katoh and K. Nozaki, Coord. Chem. Rev., 2010, 254, 2449-2458.

55 J. R. Lakowicz, Principles of fluorescence spectroscopy, Kluwer Academic/Plenum, New York, 2nd edn, 1999.

56 K. Pettersson, K. Kilså, J. Mårtensson and B. Albinsson, J. Am. Chem. Soc., 2004, 126, 6710-6719.

57 G. Baryshnikov, B. Minaev and H. Ågren, Chem. Rev., 2017, 117, 6500-6537.

58 S. S. K. Raavi, J. Yin, G. Grancini, C. Soci, V. R. Soma, G. Lanzani and L. Giribabu, J. Phys. Chem. C, 2015, 119, 28691-28700.

59 C. M. Lemon, R. L. Halbach, M. Huynh and D. G. Nocera, Inorg. Chem., 2015, 54, 2713-2725.

60 J. Vestfrid, M. Botoshansky, J. H. Palmer, A. C. Durrell, H. B. Gray and Z. Gross, J. Am. Chem. Soc., 2011, 133, 12899-12901. 
61 M. Tanabe, H. Matsuoka, Y. Ohba, S. Yamauchi, K. Sugisaki, K. Toyota, K. Sato, T. Takui, I. Goldberg, I. Saltsman and Z. Gross, J. Phys. Chem. A, 2012, 116, 9662-9673.

62 B. S. Achary, A. R. Ramya, J. B. Nanubolu, S. Seetharaman, G. N. Lim, Y. Jang, F. D'Souza and L. Giribabu, New J. Chem., 2018, 42, 8230-8240.

63 Y.-G. Wang, Z. Zhang, H. Wang and H.-Y. Liu, Bioorg. Chem., 2016, 67, 57-63.

64 L. Huang, J. Zhao, S. Guo, C. Zhang and J. Ma, J. Org. Chem., 2013, 78, 5627-5637.

65 A. Berlicka and B. König, Photochem. Photobiol. Sci., 2010, 9, 1359-1366.

66 M. Ertl, E. Wöß and G. Knör, Photochem. Photobiol. Sci., 2015, 14, 1826-1830.

67 K. Rybicka-Jasińska, B. König and D. Gryko, Eur. J. Org. Chem., 2017, 2017, 2104-2107.

68 Y. Cheng, J. Yang, Y. Qu and P. Li, Org. Lett., 2012, 14, 98101.

69 D. A. DiRocco and T. Rovis, J. Am. Chem. Soc., 2012, 134, 8094-8097.

70 K. Hanson, D. L. Ashford, J. J. Concepcion, R. A. Binstead, S. Habibi, H. Luo, C. R. K. Glasson, J. L. Templeton and T. J. Meyer, J. Am. Chem. Soc., 2012, 134, 16975-16978.

71 K. Mori, M. Tottori, K. Watanabe, M. Che and H. Yamashita, J. Phys. Chem. C, 2011, 115, 21358-21362.

72 Y. Ye and M. S. Sanford, J. Am. Chem. Soc., 2012, 134, 90349037.
73 Y.-Q. Zou, L.-Q. Lu, L. Fu, N.-J. Chang, J. Rong, J.-R. Chen and W.-J. Xiao, Angew. Chem., Int. Ed., 2011, 50, 7171-7175.

74 K. Rybicka-Jasińska, W. Shan, K. Zawada, K. M. Kadish and D. Gryko, J. Am. Chem. Soc., 2016, 138, 15451-15458.

75 C. Le, T. Q. Chen, T. Liang, P. Zhang and D. W. C. MacMillan, Science, 2018, 360, 1010-1014.

76 D. P. Rillema, J. K. Nagle, L. F. Barringer and T. J. Meyer, J. Am. Chem. Soc., 1981, 103, 56-62.

77 R. H. Clarke and R. M. Hochstrasser, J. Mol. Spectrosc., 1969, 32, 309-319.

78 A. Haefele, J. Blumhoff, R. S. Khnayzer and F. N. Castellano, J. Phys. Chem. Lett., 2012, 3, 299-303.

79 M. H. Shaw, J. Twilton and D. W. C. MacMillan, J. Org. Chem., 2016, 81, 6898-6926.

80 T. Koike and M. Akita, Acc. Chem. Res., 2016, 49, 1937-1945. 81 N. Corrigan, S. Shanmugam, J. Xu and C. Boyer, Chem. Soc. Rev., 2016, 45, 6165-6212.

82 O. V. Dolomanov, L. J. Bourhis, R. J. Gildea, J. A. K. Howard and H. Puschmann, J. Appl. Crystallogr., 2009, 42, 339-341.

83 M. C. Burla, R. Caliandro, M. Camalli, B. Carrozzini, G. L. Cascarano, L. De Caro, C. Giacovazzo, G. Polidori, D. Siliqi and R. Spagna, J. Appl. Crystallogr., 2007, 40, 609613.

84 G. Sheldrick, Acta Crystallogr., Sect. C: Struct. Chem., 2015, 71, 3-8.

85 M. J. Frisch, G. W. Truncks and H. B. e. a. Schlegel, Gaussian 03, revision E.01, Gaussian Inc., Wallingford, CT, 2007. 